\title{
The meaning of EEG indicators of loss of consciousness during anaesthesia and coma.
}

\author{
Costa Vakalopoulos \\ 171 McKean Street Fitzroy North \\ Melbourne Australia \\ Email: cvakalop@gmail.com
}

\begin{abstract}
Raw EEG changes correlate well with the effects of anaesthetics on arousal. The purpose of the present paper is to analyse the significance of the EEG spectrograph. The alpha rhythm is a signature of the unconscious and according to the MAB hypothesis (MonoaminergicAcetylcholinergic Balance) is an index of increased relative inhibitory muscarinic effects on monoaminergic modulated conscious networks. The source of alpha rhythms varies, as does the type of unconscious information: from classical occipital alpha during resting state with eyes closed where no external visual information is processed, to states of unconscious anaesthesia where alpha shifts to fronto-parietal networks. These are spontaneous oscillatory network responses and the effects of GABA agonist anaesthetics increase the amplitude of these intrinsic rhythms. The hypothesis states that the concurrent presence of sustained delta oscillations and alpha spindles signifies suppressed unconscious and conscious responses respectively, and permit neither implicit nor explicit cognition nor recollections. Further, the model will be used to interpret EEG changes associated with more atypical anaesthetics and provide reasons for the related cognitive effects. This will be based on the agents' pharmacological profiles and how they interact with these dual neuromodulatory systems. Evidence will also be drawn from EEG states associated with pathophysiology in coma and epilepsy. The pharmacological interpretation of EEG makes predictions of awareness in disorders of consciousness. The difficult circumstances of behaviourally inadequate indicators refers to situations of minimally conscious and in particular, vegetative states where decision making is fraught with uncertainty.
\end{abstract}

Keywords anaesthesia, consciousness, alpha synchrony, memory, coma

\section{Introduction}

The bispectral index (BIS) is commonly used as a measure of anaesthetic depth during a procedure. However, a recent case study of awareness during multimodal anaesthesia reveals the limitations of relying on BIS values, when a drop in the alpha spindle to low voltage gamma activity was misinterpreted as an isoelectric rhythm signal on the spectrogram (Salgado-Seixas et al., 2020). Although, Lempel-Ziv complexity (LZC) and perturbation complexity measuring entropy could become a more promising index than the BIS for reliably tracking consciousness (Bai et al., 2015; Brito et al., 2020; Wollstadt et al., 2015), it will be required to cohere with more traditional EEG measures to improve its performance (Baria et al., 2018; Boncompte et al., 2021). The aim of the present paper is to present a theoretical heuristic to EEG measures of anaesthetic-induced unconsciousness and their effects on memories during intraoperative events. The discussion of electrophysiological measures should not be interpreted as an absolute guide to clinical evaluation. A description of alpha and spindle rhythms in clinical assessment still acknowledges the importance of behavioural reactive measures. Alpha spindles are a classic signature of adequate depth of 
anaesthesia and unconsciousness during both intravenous anaesthetics such as propofol and volatile gases with only $4 \%$ of cases not showing the characteristic spectrogram of frontal alpha (Hight et al., 2017). Further, a drop out of alpha power is a response to increasing nociception and a potential marker of cortical arousal (Hight et al., 2019). So what is so special about non-occipital or fronto-parietal cortical alpha in the effects of anaesthesia and what does it tell us about signatures of the unconscious?

Although the spindle frequency range is generally regarded on average higher than typical alpha $(8-12 \mathrm{~Hz})$, they do overlap. The term sigma will be avoided in this paper to highlight the importance of cholinergic muscarinic mechanisms proposed to underlie both. In rats, spindling does not occur with combined cholinergic and aminergic blockade linking it to neurotransmitter modulation (Dringenberg and Diavolitsis, 2002). A slower alpha has also been discussed in the literature that drifts into a theta range i.e. during sleep. The author acknowledges a certain arbitrariness in defining potential frequencies under different states and hopes the hypothesised pharmacological mechanisms will unite the concept of a behavioural unconscious equivalent in an alpha family of rhythms (Lawhern et al., 2013). Transitional inhibitory states should also be kept in mind. Slowing of the rhythm prior to establishment of full anaesthesia goes through a beta phase and associated sedative effects i.e. a transition between gamma and alpha EEG signals (Pavone et al., 2017). Persisting low beta spectral power can shift alpha to a higher frequency. The author will also embrace this principle with regards to a delta spectrum of rhythms, but currently excludes ultra slow hyperpolarizating delta i.e. below $0.5 \mathrm{~Hz}$, the significance of which is still obscure.

The MAB hypothesis is the cornerstone of the present theory. It posits an understanding of cognition and memory acquisition as parallel implicit and explicit networks or traces. The strength of the model is the explanation of dissociated EEG signatures that index these separate memory traces. MAB is the pharmacological basis of the dual model of cognition that has a long folk psychological tradition. It states that delta and alpha rhythms are induced by a relative excess of cortical monoamines and cholinergic agonism, respectively. During states of awareness normal waking monoamine and acetylcholine ACh levels desynchronize the EEG, which shows the widespread gamma activity of an arousal state. This is dependent on excitatory $\mathrm{G}$ protein transducing events balancing the EEG slowing down effects of inhibitory receptor subtypes. The MAB hypothesis predicts that a relative decrease in either neurotransmitter induces generalized synchronization at either alpha or delta frequency ranges. A selective drop in excitatory transduction in one of the parallel networks unmasks inhibitory $\mathrm{K}+$ currents necessary for slower synchronous rhythms. Thus, the muscarinic antagonist atropine elicits widespread delta activity (Schaul et al., 1978) and tacrine, an acetylcholinesterase inhibitor, increases alpha power while concurrently decreasing delta (Dringenberg et al., 2000). Importantly, in the latter study, which used reserpine to deplete monoamines and the muscarinic antagonist scopolamine, robust restoration of gamma activity required a concomitant increase in serotonin levels by administering fluoxetine, a serotonin transport inhibitor. Tacrine alone was less effective. This supports the principle that high levels both of monoamines and $\mathrm{ACh}$ are required for arousal related gamma activity and that EEG rhythms are finely tuned to their relative levels.

Typical volatile and intravenous anaesthetics reduce activity in both monoaminergic and cholinergic projections and this overall effect decreases the ratio of excitatory/inhibitory transmission. Deactivation of excitatory receptors by reduced neuromodulator levels is proposed to unmask inhibitory receptors and the further relative balance between monoamines and ACh determines the signature of EEG synchrony i.e. alpha or delta (figure 
1). This is supported by another study in rats, which showed increases in slow brain activity with concurrent monoamine depletion and muscarinic ACh receptor antagonism through scopolamine administration (Dringenberg and Diavolitsis, 2002). Alpha, furthermore is selectively suppressed with subsequent enhancement of serotonergic function with fluoxetine.
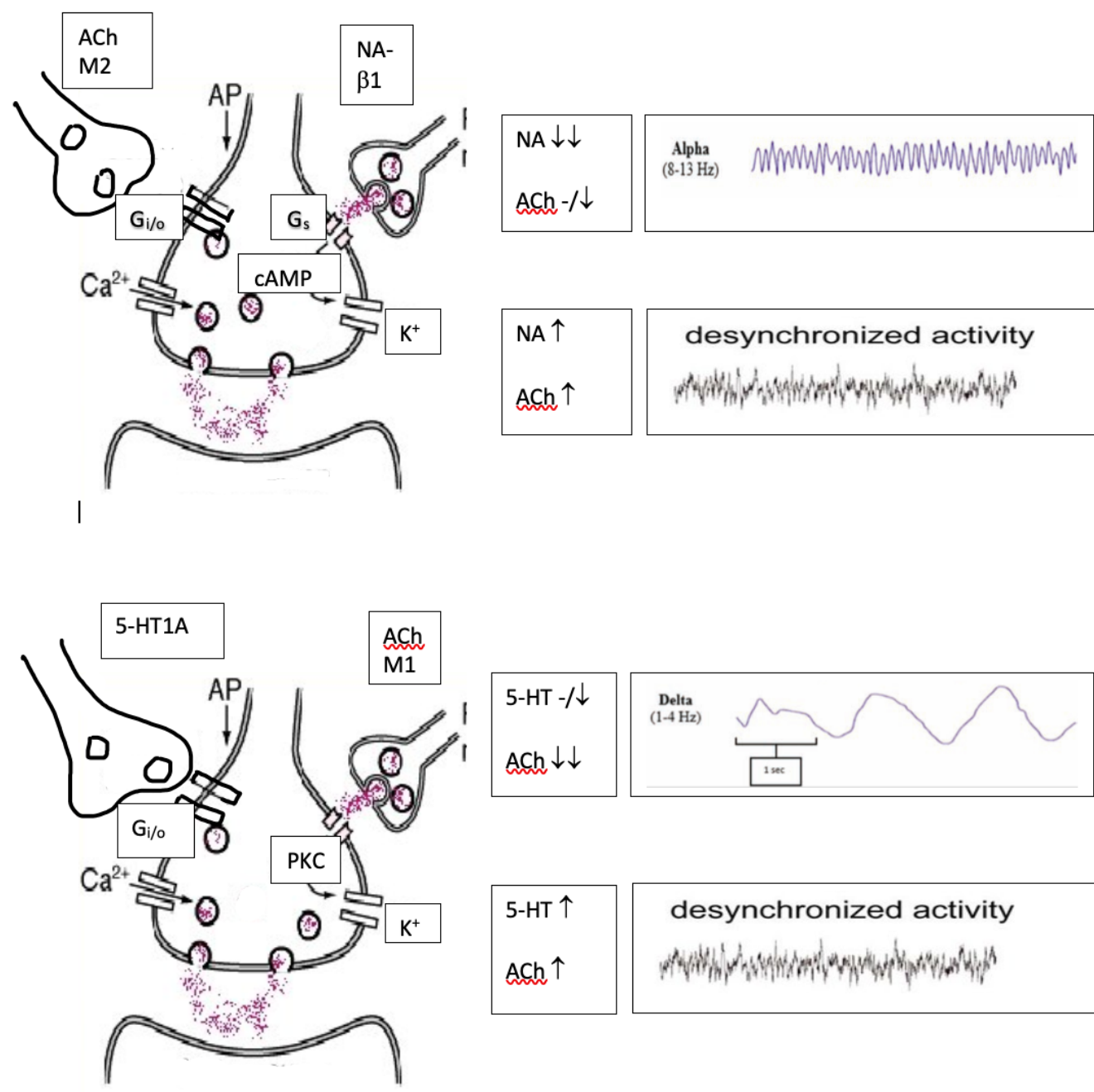

$5-\mathrm{HT}-/ \downarrow$

ACh $\downarrow \downarrow$

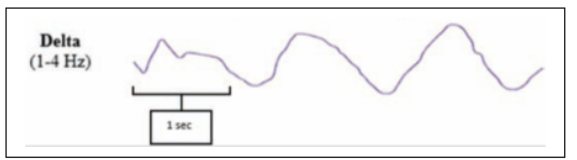

$5-\mathrm{HT} \uparrow$

$\mathrm{Ach} \uparrow$

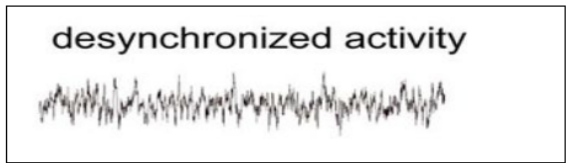

Figure 1. Heterosynaptic or diffusion of monoamines and acetylcholine: inverse modulation of the EEG. The role of GABAergic input at certain harmonics in synchronizing and increasing amplitude of oscillations is addressed in a later section.

During anaesthesia high amplitude alpha and delta oscillations are typical signatures of loss of reactivity, not just of conscious awareness. This is because sustained normal or even relative levels of either monoamines or ACh individually, would enable processing of information and potential behavioural responsivity. Information processing may persist when either implicit or explicit cognitive function is preserved under anaesthesia. MAB proposes that the dual cognitive substrates are differentially modulated by separate classes of neurotransmitters and represented by spectral power of lower frequencies on the EEG. Such a statement is not obvious, but one can start to speculate on these roles even from preliminary evidence garnered from the use of psychedelics, which are serotonin receptor agonists and anticholinergics. Both drug classes can render hallucinatory reports. 
The inverse nature of the antagonism between neuromodulators generates the unique signals signified by delta and alpha rhythms. These, in turn will be regarded as putative indirect indices for conscious and unconscious information processing. The fact that they are indirect is alluded to by the demonstration of ongoing nested gamma activity. Conversely they are direct measures of cross inhibition of parallel network activity. The key point here is that behavioural responsiveness can result from either explicitly or implicitly i.e. unconsciously or non-phenomenologically, motivated actions. This is the starting point for resolving difficulties in interpretation of what constitutes EEG markers for unresponsive sedation i.e. a theory that challenges the intuitive concept of cognition as a single, serial entity.

\section{Event Related Potentials}

A consequence of the idea of inhibitory rhythms is that slow oscillatory activity in alpha and delta frequencies suppress ERP responses to external stimuli associated with conscious and subconscious potentials, respectively e.g. P300 (Plourde and Picton, 1991) and N100 (Yppärilä et al., 2004). However, P300 response was absent in several cases still responsive during propofol sedation (Sneyd et al., 1994). However, it wasn't clear whether these were aware or simply automatically responsive, highlighting a concern addressed by the theory of parallel cognitive processes. There is an ongoing debate about whether P300 (or P3b) is an actual marker for conscious awareness or a reflection of post-perceptual processing and decision making (Cohen et al., 2020; Sergent et al., 2021), an interesting question that won't be explored here.

Further evidence of the specificity of oscillation frequency comes from a study where progressive loss of awareness was strongly linked to alpha power in the 8-14 Hz frequency range in human volunteers under propofol anaesthesia (Supp et al., 2011). Late-latency somatosensory evoked potentials (140-370ms), but not early (0-90ms)- nor mid (30-110ms)latency components were negatively correlated with frontal alpha power. Late-latency corresponds roughly to P300 ERP a measure of the conscious awareness of the stimulus and mid-latency to N100, a preattentive ERP measure ${ }^{1}$. Importantly, a completely unresponsive state was marked by a sudden reduction in alpha power. These contradictory findings are consistent with the concept that automatic responses to sensory stimuli are not being directly down-modulated by frontoparietal alpha oscillations in the first case, but are an indirect positive index for such responses in the second case. The delta signal predicts suppression of preattentive or 'automatic' related behaviour. Likewise mid- but not early-latency components vanish at this depth of anaesthesia simultaneous to a loss in alpha power i.e. although alpha power represents inhibition of conscious awareness, its presence signals potential expression of covert activity, which can be further inhibited by delta power increases. Fourier analysis of delta power was not performed and the authors suppose that

\footnotetext{
${ }^{1}$ A tonal frequency discrimination study during anaesthesia demonstrated greater than zero P300 and N100 for hits at preinduction and were not significantly above zero during surgery (Plourde and Picton, 1991). However, both ERP markers were absent during hits in a minority of subjects during emergence only. One ought to refrain from considering any marker of cognitive process as an absolute or equivalent, but view them as consistent, if not powerful indices only, and that they can vary under different neurophysiological conditions. For example, the hits during emergence demonstrated a biphasic waveform similar to N100/P300 but at 500-600ms. Reaction times for hits increased by $\sim 300 \mathrm{~ms}$, which corresponds to the observed latency increases in putative ERPs. In other words, ERP markers may not have been absent all, but longer latency.
} 
unresponsiveness might correlate with incipient burst suppression, obscuring differential markers of implicit and explicit cognitive inhibition.

\section{An anatomical substrate for alpha and delta}

The proposal that ERP signals are processed in parallel cortical networks suggests that spectral differentiation of alpha from delta has an anatomical as well as pharmacological basis. The anatomical foundations of unconscious and conscious information processing are described in a previous theoretical dissertation (Vakalopoulos, 2005a, 2008). The present insights build on a model of segregated thalamocortical networks serving explicit and implicit cognitive categories: the dorsal thalamus and largely feedforward input to layer IV of the granular cortex and the intralaminar and midline, or 'non-specific' thalamus with its diffuse connections predominantly to supra- and infragranular layers of the cortex, respectively. The model spells out a kind of symmetrical correlation with the dominant spectral signatures under non-responsive anaesthesia and potentially explains why a high level of spontaneous Lempel-Ziv complexity or PCI (TMS-evoked approach) better tracks consciousness during high amplitude delta oscillations (Frohlich et al., 2021). In other words, complexity, as an index of preserved cognitive function, is nested in this cortical anatomical parallelism.

Evidence that sleep spindles incompletely suppress auditory information reaching the cortex (Dang-Vu et al., 2011) and interfere with transmission through the principal thalamic nuclei (Andersen et al., 1967a) is consistent with the notion that alpha oscillations selectively inhibit conscious perception. Importantly, normal spindles remained in the lateral thalamus and frontal cortex after comprehensive bilateral lesions of the midline and intralaminar thalamus (Andersen et al., 1967b) consistent with this parallelism. In contrast, lesions of the lateral thalamus had profound effects on spindle generation in the ipsilateral cortex. Putative generators of spindles have variously been described as emanating from supragranular, infragranular and granular layers (the latter is a main input of dorsal thalamus) in all sensory modal cortices and either drive thalamic spindles in awake subjects (monkeys and humans) (Haegens et al., 2015; Halgren et al., 2019) or follow them during NREM sleep (MakMcCully et al., 2017). The variation in findings suggests a more comprehensive third source of neuromodulation intrinsic to oscillation formation.

These findings support the contention that there are two parallel corticothalamic systems, typically described as specific and non-specific projections, but identified in a previous theoretical paper with conscious and subconscious cortical networks. The model describes a developmental history of the interacting organism with its environment and acquisition of the respective algorithms underlying dual cognition and mediated by motor efference copy (Vakalopoulos, 2005a, 2005b, 2008). Electrophysiological correlates of dynamic suppression in either extant network is manifested as EEG alpha and delta spectral phenomena. Thus anatomical substrates reinforce the pharmacological model of dissociative conscious and subconscious behaviour. Recapitulating thoughts on non-reactivity during anaesthesia, it's not simply a question of paralysis of movement or even explicit recollection, but further modulation of implicit processing. The latter can retain emotional traces of subconsciously perceived events.

\section{Alpha or delta and what of gamma?}


Identifying alpha and delta rhythms with separate pharmaco-anatomical substrates resolves the theoretical dilemmas posed in explaining totally unresponsive as distinct from simply unconscious correlates of anaesthetic spectral analysis (Stephen et al., 2020). The authors attempt to integrate two separate events under a single causal structure by proposing delta entraining of all alpha rhythms, weakening the theoretical importance of alpha. This entails entertaining the tenuous idea of cortical up- and down-states to explain timing of arousal. According the present theory, such models erroneously attribute probability of response to peaks and troughs. High frequency bursts alternating with hyperpolarization drive the oscillation and are a spurious signal i.e. not a marker of cognitive activity. Of course, there is a cross modulating effect of delta and alpha oscillations on gamma rhythms of the networks on which they act. Conversely, there is a nested gamma emanating from a parallel network to that modulated by an individual slow oscillation. However, both gamma and alpha, or delta and gamma are generated selectively, but not concurrently, by the same neuromodulator in parallel i.e. the detection of gamma in either context signals desynchronizing activity in a network separate from the one directly modulated by narrow band slow oscillating activity. This excitatory/inhibitory balance has a parallel generated inverse relation ${ }^{2}$.

Arousal would in principle be tracked by PCI index, but Lempel-Ziv complexity need not only be associated with emergent conscious awareness in a dualistic model. Complexity may also increase with pharmacological manipulation of the cognitive unconscious using cholinergic agonists to reverse the modulatory effects of slow delta amplitudes on preconscious processes and concurrently, increasing gamma activity while anaesthetic agents maintain a parallel 'phenomenologically' unconscious state. (These two current uses of the term unconscious should not be confused!). In principle, the dual cognitive model resolves the paradox inherent in a study that showed desynchronizing activity of carbachol administered to rat parietal cortex and increasing complexity, but not awareness (Pal et al., 2020). The study leaves many questions unanswered though, as it restricted spectral analysis to the low delta range, failed to look at effects on spindling, which is specific to conscious awareness. Nor did it assess concurrent administration of carbachol and noradrenaline NA, which would more typically result in emergence ${ }^{3}$.

The MAB hypothesis provides a heuristic approach to understanding qualitative and spatial differences in alpha spindling that is based on relative rather than absolute levels of neuromodulator synaptic concentrations. Regional differentials in neuromodulator balance explain the independence of spindles from delta oscillations. For example, local spindles during NREM sleep occur without spindle activity in other cortical areas including homotopic regions across hemispheres with global slow waves (Andrillon et al., 2011). The

\footnotetext{
${ }^{2}$ The task of differentiating the many sources of gamma activity and establishing their varied significance is not straightforward. It remains fortuitous that the two signals representing dual cognitive inhibition, as proposed by the MAB hypothesis, coalesce around separate slow spectral bands.

${ }^{3}$ Much more can be said here about what is necessary and sufficient in a theory predicting a conscious phenomenology beyond electrophysiological markers such as EEG, complexity and pharmacology. Postulates should include anatomical correlates like the requirement for activation of both dorsal and ventral pathways and how a threshold of preconscious activation serves as an alerting mechanism that orients conscious attention or leads to activation of awareness (e.g. carbachol in the frontal cortex elicits arousal through higher ACh levels than when applied to the parietal cortex, which does not; or why application of a single monoamine like NA doesn't generate awareness). A more nuanced discussion of the Pal et al. findings in beyond the scope of this paper.
} 
relative ratio of specific monoamines and $\mathrm{ACh}$ might also prove useful in explaining regional differences in frequency with the demonstration of faster centroparietal versus slower frontal spindles (Fogerson and Huguenard, 2016). The classic study of the EEG with eyes closed elicits occipital alpha. Although widespread power increases also occur for all lower frequencies, eye closure causes comparatively focal high frequency reductions over occipital cortex and frontal areas 8 and 9 (Geller et al., 2014). This can be explained by a lack of engagement of neuromodulator activity that is partially region selective.

\section{Sharp wave ripples (SWR): alpha, delta and gamma}

One of the more intriguing aspects of the EEG occurs during slow wave sleep (SWS) or NREM, where and underlying delta rhythms is punctuated by alpha spindles and hippocampal sharp wave ripples. These latter are high frequency gamma bursts $(80-100 \mathrm{~Hz}$ in humans) that co-occur with cortical high frequency bursts (Khodagholy et al., 2017). Only a small proportion of SWR are coupled to spindles, but most spindles are coupled to SWR (Aleman-Zapata et al., 2020). A common external factor in ripple-spindle coactivation was presciently surmised to be due to a common external factor namely, the 'ascending activating reticular projections' (Siapas and Wilson, 1998). Only a subset of SWR are associated with a phasic drop in metabolic activity in the serotonergic dorsal raphe (DR) and noradrenergic LC in the macaque (Ramirez-Villegas et al., 2015), lending support to a dualistic view of neuromodulatory behaviour. These brainstem nuclei ramify profusely throughout the brain. Hippocampal ripples are nested in the troughs of spindles, with ripple power increasing around the spindle centre and conversely, there is a significant increase in spindle power around the ripple centre (Staresina et al., 2015). There was also prominent modulation of ripple power in this study, by the delta spectral band, maximal at $\sim 3 \mathrm{~Hz}$. These findings are a powerful confirmation of the MAB model of inverse and antagonistic neuromodulation to parallel network activity. The unmasking of spindles and what relation that might have to cholinergically modulated networks is addressed in the next section. For the role of SWR in memory consolidation see Appendix B.

\section{Pharmacological mechanisms of slow waves and spindles}

MAB states that alpha spindles and delta slow oscillations represent inverse pharmacological effects on colocalized $\mathrm{G}_{\mathrm{i} / \mathrm{o}^{-}}$and $\mathrm{G}_{\mathrm{q} / 11^{-}}$or $\mathrm{G}_{\alpha \mathrm{s}}$ subsets of receptors (figure 1). Receptor subclasses respond to relative levels of monoamines and ACh. Cyclical hyperpolarizing GIRK (G protein inwardly rectifying $\mathrm{K}+$ current) activation and rebound depolarizations is proposed to produce distinct high amplitude rhythms in the alpha and delta spectral ranges (Vakalopoulos, 2014). For example, 5-HT2A/M2 and 5-HT1A/M1 receptors colocalize generating distinct oscillatory activities depending on the predominant neuromodulator. If both monoamines and $\mathrm{ACh}$ are present at waking levels stimulatory, depolarizing effects on neuron activity prevail, which desynchronize the rhythm.

More generally a monoamine $\mathrm{G}_{\mathrm{i}}$ receptor signal is juxtaposed against muscarinic $\mathrm{G}_{\mathrm{s}} / \mathrm{G}_{\mathrm{q} / 11^{-}}$receptor subtype and vice versa. So if one neurotransmitter class drops in activity, say serotonin, then M2 signal will dominate generating alpha type rhythms. Conversely, if ACh corticothalamic modulation is reduced, 5-HT inhibitory receptor subtypes become predominant in generating delta rhythms. The mechanism is necessarily simplified to illustrate overall proposed effects, but suffices as an overall explanandum. Thus, in emergence from anaesthesia as neurotransmitter levels rise and activate respective 


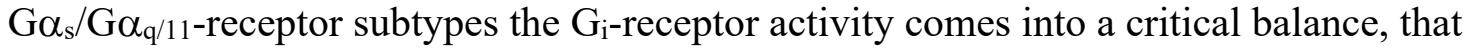
favours desynchronization and thus, awareness-related gamma activity.

The serotonergic hallucinogen psilocybin reduced prestimulus alpha and blocked parietooccipital alpha power increases and the effect was antagonized by the 5-HT2A receptor preferring antagonist ketanserin (Kometer et al., 2013). This is consistent with the inherent antagonism between serotonin related transduction of $\mathrm{G}_{\mathrm{q} / 11}$ signalling and $\mathrm{M} 2$-like $\mathrm{G}_{\mathrm{i} / \mathrm{o}}$ pathways. In rats, serotonin (5-HT2) subtype receptor antagonists increased alpha amplitude and power of high voltage spindles during quiet rest (Moyanova et al., 1998). Ketanserin increases spindles at higher concentrations only, where in addition to 5-HT2A antagonism it also displays antagonistic activity at noradrenergic $\alpha 1$ receptor (Jäkälä et al., 1995) illustrating one limb of monoamine-ACh neuromodulation. That a parallel network exists is suggested by neuromodulation of delta rhythms by activity at 5-HT1A. The 5-HT1A antagonist NAN-190 reduced the power density in the delta range (Neckelmann et al., 1996), whereas the agonist 8-OH-DPAT increases slow wave activity during NREM sleep (Monti and Jantos, 1992) and this appears to occur at the heterosynaptic 5-HT1A receptor. The anomaly that $\alpha 2$ reduces spindles is solved by a presynaptic activity on noradrenergic terminals increasing NA release and is more parsimonious with the demonstration that $\alpha 1$ antagonist increases spindles and antagonizes $\alpha 2$ antagonist-induced increases (Buzsáki et al., 1991; Riekkinen et al., 1993).

\section{Evidence for a muscarinic role in spindling}

The appearance of EEG spindles is a reliable indicator of depth of anaesthesia (Keifer et al., 1994). Spindling (classically described in stage 2 sleep) also overlaps with the alpha frequency band. Is transduction through the muscarinic M2 subtype important for spindle production? Spindle activity can be elicited in isolated cortex with the local application of eserine and acetylcholine (Kristiansen and Courtois, 1949). Microdialysis of an M2 receptor antagonist in the mouse prefrontal cortex reduces the number of spindles $(7-14 \mathrm{~Hz})$ under halothane anaesthesia (Douglas et al., 2002). The authors assumed that loss of slow wave activity is due to presynaptic receptor occupation increasing ACh release and thus, having an activating effect. But, the desynchronizing effects of M1-mediated cortical ACh (presynaptic M2 blockade would increase available synaptic ACh) and the potential postsynaptic target of M2 inhibitory signals offer a different account of the findings i.e. selective M2 muscarinic antagonists are predicted to have a direct effect on mitigating alpha rhythms.

An in vivo optogenetic stimulation of mouse cholinergic basal forebrain projection to the TRN 'paradoxically' shortens the latency to sleep onset and causes spindle oscillations associated with NREM sleep (Ni et al., 2016). The authors show a nicotinic receptor dependence, but muscarinic receptor subtypes are also likely involved as they are present in TRN (Beierlein, 2014). Further, localized infusions of a muscarinic M2 antagonist into the thalamic reticular nucleus suppresses this spindle activity (Puoliväli et al., 1998). However, cholinergic effects can be complex, especially if administered systemically with both pre- and post-synaptic M2 receptor effects and other authors offering different interpretations of spindle suppressive effects (Jäkälä et al., 1996). For example, cholinergic agents including acetylcholinesterase inhibitors and direct muscarinic receptor agonists decrease high-voltage spindles in rats (Jäkälä et al., 1996). However, this is associated with desynchronization and thus, general arousal mechanisms that would switch off $\mathrm{K}+$ currents. Part of the mechanism 
may be indirect, implying activation of brainstem monoaminergic nuclei. The aforementioned interpretations of data are a testament to the versatility of MAB in explaining complex relationships of pharmacological agents with receptor subtypes and homo- and heterosynaptic effects on oscillatory rhythms.

\section{Basal forebrain and brainstem projections}

The inverse pharmacological relationship is manifest in studies following mesencephalic section (cortical monoamine depletion) associated with regular bursts of alpha activity, citations of Bremer within (Kristiansen and Courtois, 1949). Conversely, an increase in delta (1-4 Hz) was produced by procaine injections into the basal forebrain, which reduces cholinergic and GABAergic input to the cortex (Cape and Jones, 2000). In addition to a decrease in gamma activity, there is a loss of paradoxical sleep and persistence of slow wave sleep, SWS. A separate population of GABAergic from those discharging during wake and REM sleep stages were active during SWS and positively correlated with delta oscillations (Hassani et al., 2009). It is not clear however, why more selective lesions of the cholinergic basal forebrain in rats does not lead to alpha power changes (Holschneider et al., 1999; Kaur et al., 2008) even if data from cholinergic deficiency in humans showed marked deficits (see Appendix A).

Confirmation of inverse relations comes from the observation of the transitory decrease in dorsal raphe unit activity a few seconds immediately preceding a spindle, remaining low during spindle activity and then increasing immediately after the spindle (Trulson and Jacobs, 1979). This feature was found across all stages of SWS. A similar analogy can be made of noradrenergic systems. A decrease in NA firing during SWS facilitates cortical spindling between $0.5-1 \mathrm{~s}$ later and an increase in discharge terminates spindling (Aston-Jones and Bloom, 1981). The importance of these two findings cannot be overstated as SWS is marked by delta activity and lowest cholinergic tone during the sleep wake cycle. Indeed, one study asked why hyperpolarization during NREM sleep wasn't sufficient in itself to generate spindles but required further tightly coupled slow wave down state-induced hyperpolarization (Mak-McCully et al., 2017). The down state, up to $2 \mathrm{~Hz}$, did overlap with classical delta, but not all spindles are so coupled. A parsimonious resolution of the problem is hinted at by the association of spindle generation with acute drops in monoamine activity, deactivation of excitatory transducers, thus increase in hyperpolarizing $\mathrm{K}+$ currents altering MAB.

\section{Correlates of alpha and delta power in the EEG of anaesthesia}

Loss of consciousness during modern day anaesthesia using intravenous propofol is coincident with low frequency EEG power increases (figure 2) in both anteriorized alpha and slow delta $(0.5-1 \mathrm{~Hz})$ bands (Purdon et al., 2013). Coherent thalamocortical delta oscillations (1-5 Hz) emerge during deep levels of unconsciousness (Flores et al., 2017). 


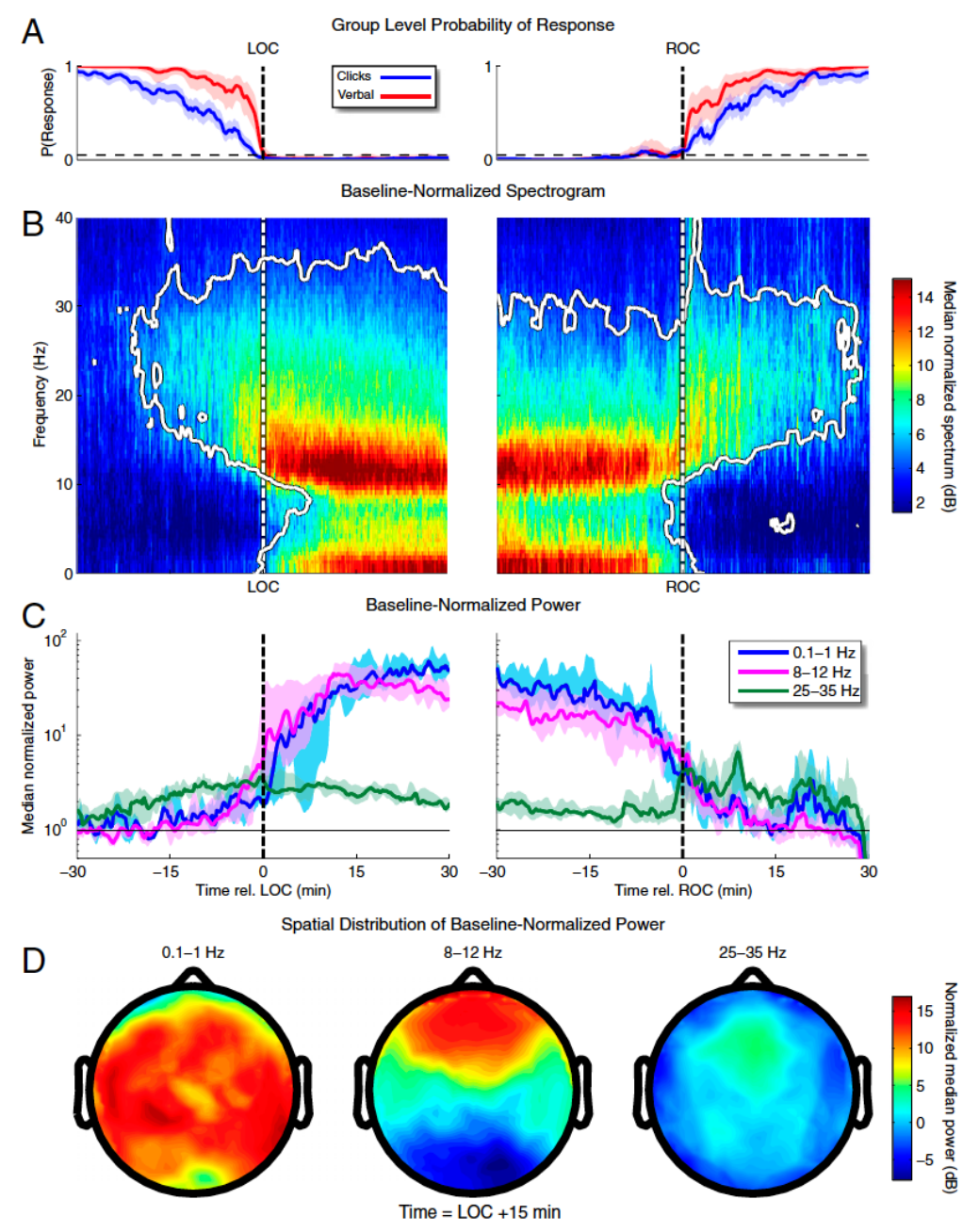

Figure 2. Dynamics of the EEG spectrogram during induction and emergence from propofol-induced unconsciousness. (A) Group-level click (blue, $P_{\text {clicks }}$ ) and verbal (red, $P_{\text {verbal }}$ ) response-probability curves, as shown previously in Fig. 1D. (B) Group-level baseline-normalized spectrograms from a frontal channel (approximately Fz, nearest-neighbor Laplacian reference) aligned with respect to LOC and ROC. The white contour circumscribes the regions where power differs significantly from baseline ( $\mathrm{P}<0.05$, sign test) and indicates significant increases in power spanning low-frequency $(0.1-1 \mathrm{~Hz})$ through gamma $(25-35 \mathrm{~Hz})$ bands. (C) Group-level time course of power in lowfrequency, alpha $(8-12 \mathrm{~Hz}$ ), and gamma bands aligned with respect to LOC and ROC. (D) Grouplevel spatial distribution of low frequency alpha, and gamma power during unconsciousness (LOC + 15 min). Permission from Purdon et al., 2013.

Volatile anaesthetics such as sevoflurane are associated with a similar pattern of EEG changes with delta- or spindle-dominant traces (figure 3) and burst suppression during more profound anaesthetic maintenance (Chander et al., 2014). Appearance of spindles (11-15 Hz) during normal sleep is considered the hallmark of stage 2 sleep (Dang-Vu et al., 2011). Only during deeper NREM sleep are spindles reduced and slower oscillations more prominent. Consistent with the preeminent importance of alpha rhythms in LOC, barbiturates produce spindles but no delta oscillations (Nuñez et al., 1992) and thalamocortical coherence is markedly increased during this type of anaesthesia (da Silva et al., 1973). 

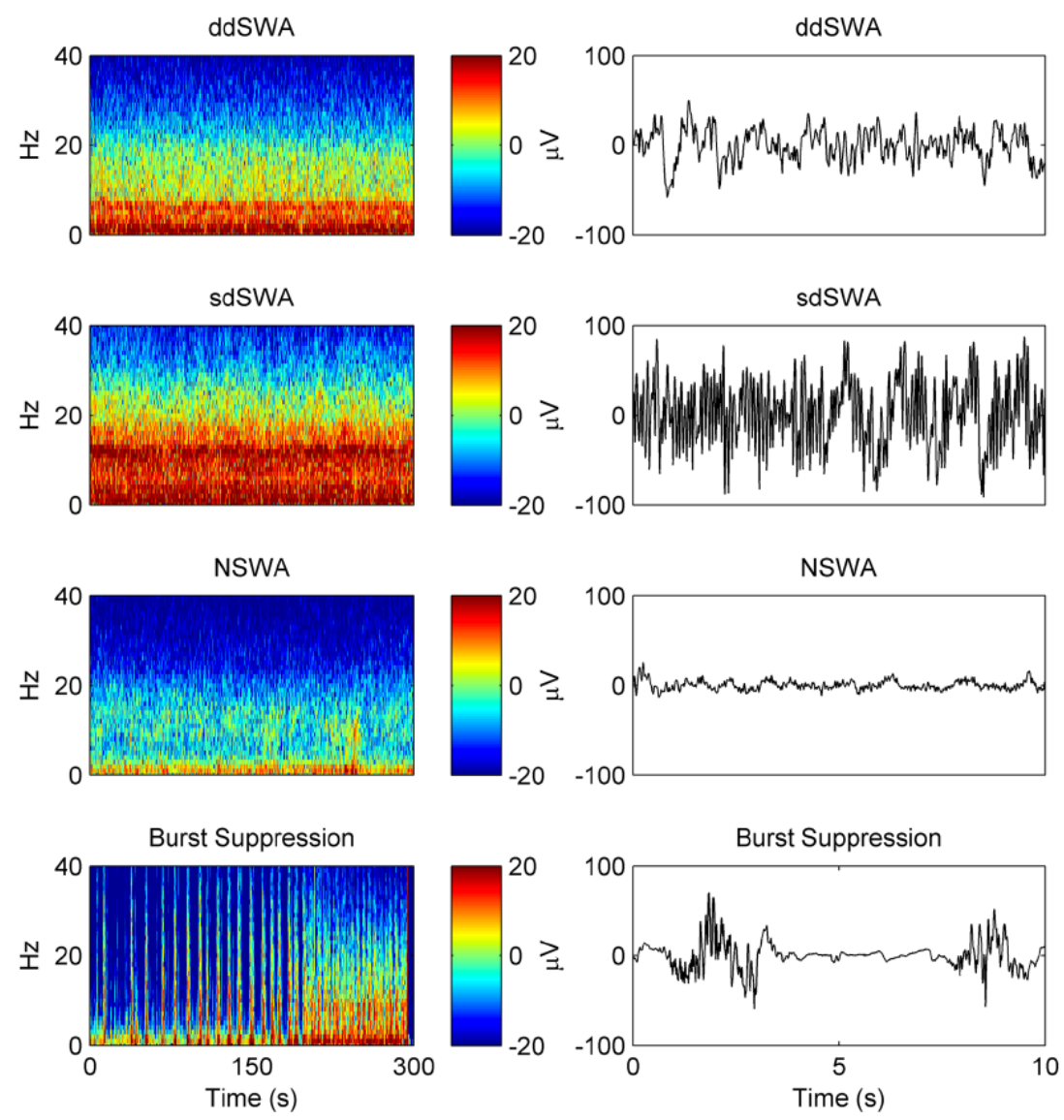

Figure 3. Spectral patterns at the end of maintenance under sevoflurane general anesthesia comprise 4 basic patterns. 'Slow-Wave Anesthesia' (SWA) is a spectral pattern in which there is both high delta and spindle power (.7 dB). Panel (A) shows the more common variant, or subclass, of the SWA spectrogram, calculated over 5 minutes prior to turning off the anesthetic, in which delta power is higher than spindle power (point \#1 below the diagonal in Figure 2B) termed delta dominant SWA, or ddSWA. An example 10 second raw EEG tracing is take from this period and shown in the right column. Panel (B) is an SWA spectral variant/subclass in which spindle power is higher than delta power, termed spindle-dominant SWA, or sdSWA (point \#2 above the diagonal in Figure 2B). Finally, a small subset of patients (5\%) showed low amplitude power in both the spindle and delta frequency bands (C). We termed this pattern non Slow-Wave Anesthesia, or NSWA (point \#3 in Figure 2B). For completeness, the spectrogram in panel (D) reflects a deeper anesthetic maintenance pattern, burst suppression, transitioning into a ddSWA pattern at approximately 1.5 minutes prior to End Maintenance. The representative 10 second EEG to its right is taken from the burst suppression period (Chander et al., 2014).

Nonetheless unconsciousness is typically associated with high amplitude activity concentrated in both the alpha and delta bands (Ching et al., 2010). Neurophysiological data and sleep studies suggests an incompatibility between spindles and delta oscillations more generally (Nuñez et al., 1992) and can be explained by the MAB hypothesis of an inverse pharmacological relationship. How is the theory compatible with the unique situation demonstrated during anaesthesia and occasionally during SWS of concurrent spindles at the peak of delta waves? Here one needs to look at the differential effects anaesthetics have on receptor subtypes both directly and indirectly. In addition to the inverse laws of MAB, there is an anatomical presupposition of parallel networks of subconscious and conscious cognitive instantiations displaying pharmacological complementarity. Under certain conditions this permits the suppression of both and is addressed under the section on molecular mechanisms 
of anaesthetics. Indeed that is the aim ultimately of anaesthetics to render inactive all complex cognitive processing.

\section{Dealing with the alpha contradictions}

An apparently counterfactual study demonstrated volitional responses to verbal command in 3 of 90 anaesthetized patients with alpha-delta frontal dominant pattern (Gaskell et al., 2017). Another 3 responders administered ketamine did show an expected emerging rhythm. It remains premature and somewhat artificial to couch this finding in terms of a Popperian falsification as the authors suppose. Frontal alpha on EEG is not a fully developed paradigm of unconscious activity. Frontal alpha (or delta), is only an approximate index of the extent of alpha modulated networks and it remains plausible that critical areas related to conscious awareness (i.e. parieto-temporal) did not demonstrate adequate alpha synchronization coherent with frontal measures. Consistent with this explanation is that only a very small minority of subjects actually reveal the intact frontal alpha/delta pattern when responding. The onus still remains equally with the authors as to why alpha/delta is the dominant finding as it is incumbent on those that view alpha as an index of lack of awareness to explain the small number of exceptions. Consistent with this explanation is the findings that sleep onset is associated with stage 2 sleep, appearance of spindles and dispersion of alpha rhythms from occipital to more anterior and in particular, centroparietal scalp locations (De Gennaro et al., 2001; Sejnowski and Destexhe, 2000).

A plethora of literature has not shown profound alterations in consciousness associated with frontal lobe lesions and the authors make this point clear. Similarly, while quiet rest with closed eyes generates classical occipital alpha, patients are aware in other ways, including the potential for visual imagery, whilst visually unaware of their external environment. A case can be made for the critical inclusion of the parietal lobe and especially temporo-parietal junction (TPJ). Awareness in different sensory modalities are served by different associative cortices. Even as such, it is not difficult to find counterexamples when EEG markers are treated as a superficial phrenology. In this regard, the authors are correct in considering looking elsewhere for an explanation of loss of awareness during anaesthesia, but this must entail the meaning of the alpha spectrum as a marker of the unconscious.

The usefulness of the dual cognitive model can be illustrated in the interpretation of an elegant study that showed an association between unresponsiveness during the onset and offset periods of sevoflurane anaesthesia and a concurrent drop in resting occipital and frontal alpha (Pavone et al., 2017). Conversely, intermittent responsiveness is positively correlated with frontal and occipital alpha power (figure 4). During stable anaesthesia, responsiveness can be occasionally seen during an absence of prominent delta oscillations. To quote the authors directly: We conclude that awake-alpha oscillation, previously thought to be an idling rhythm, is associated with responsiveness to behavioral stimuli. This would normally 
A

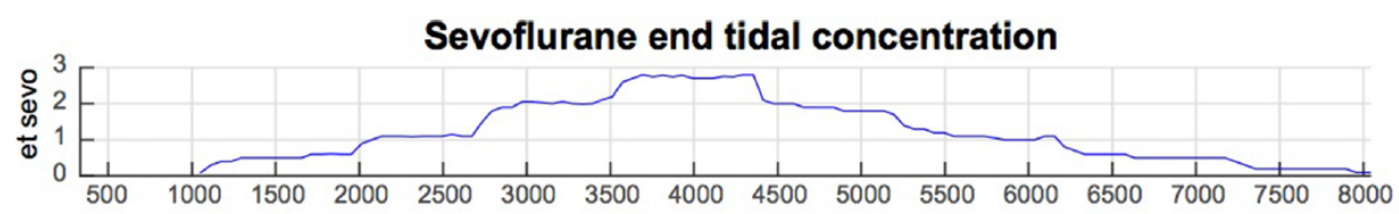

B
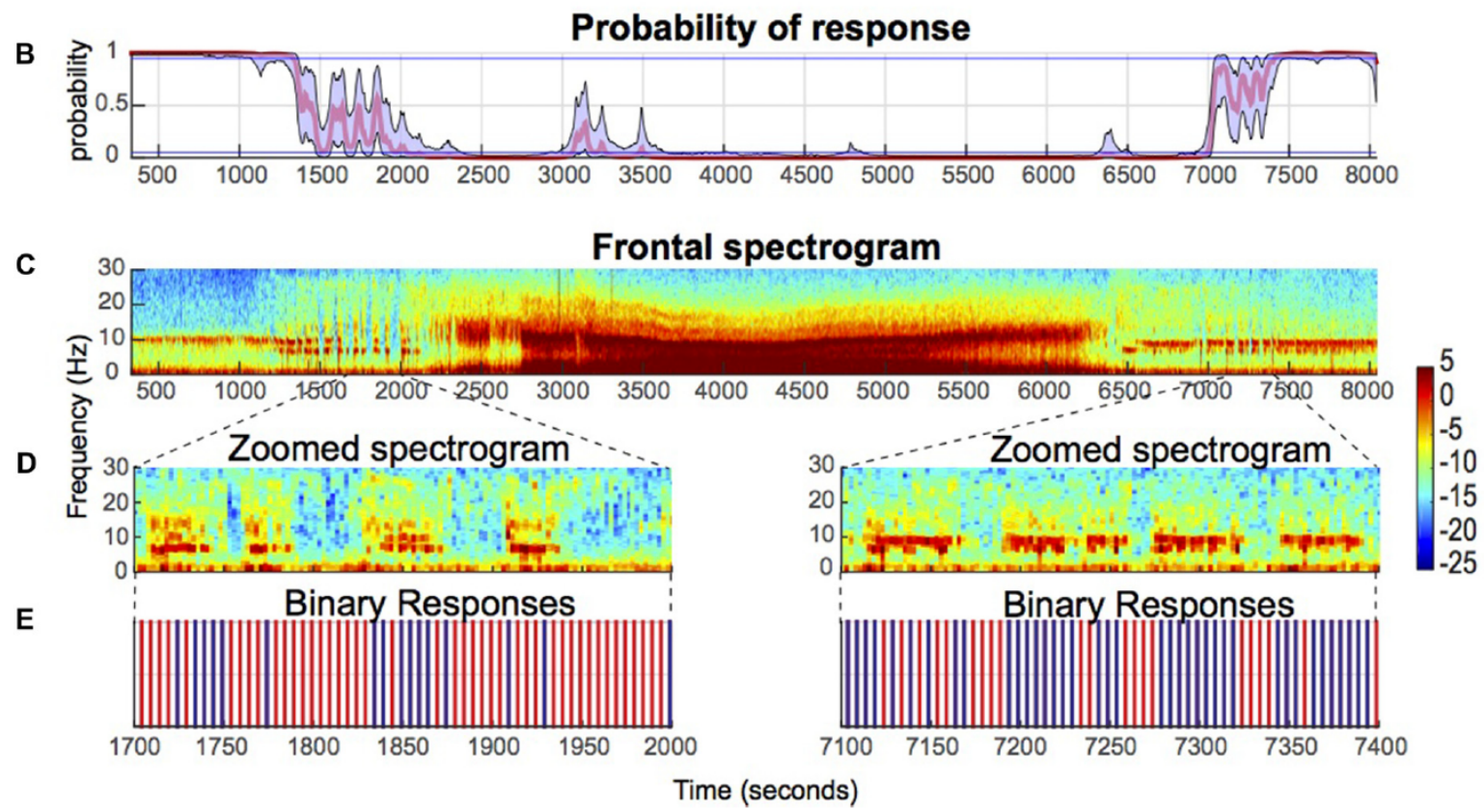

Figure 4. Illustrative electroencephalogram (EEG) spectrogram of a healthy volunteer during induction and emergence from sevoflurane-induced unconsciousness. (A) End tidal sevoflurane concentration during induction and emergence. (B) Behavioral stimuli response-probability curve corresponding to (A). (C) EEG spectrograms from a frontal channel (approximately Fz) corresponding to $(\mathrm{A}, \mathrm{B})$ above show that sevoflurane-induced oscillatory dynamics are closely associated with altered arousal. (D) Zoomed in spectrogram during effect-onset and -offset. (E) Binary response demonstrates that loss of awake-alpha is correlated with lack of response (red) to behavioral stimuli (Pavone et al., 2017).

present an anomaly for alpha as an indicator of an unconscious (unresponsive) anaesthetic state. However, the current model describes the alpha rhythm as an index of preattentive processing and thus, subconscious or 'automated' responsivity. A complete lack of behavioural response to stimulus then, requires both explicit and implicit cognitive suppression as measured by alpha and delta EEG power, respectively. Of course, there were major differences in alpha power between waking and general anaesthesia in the study that potentially factor into the fragility of the sedative state and that may permit explicit responses as well. Finally, the dual model can explain the dissociation of sevoflurane offset alpha peak responsiveness, albeit of smaller amplitude, compared to no alpha peak for the onset condition. Here alpha is an indirect index of parallel functional agonism, but itself a direct marker of suppressed activity. The authors correctly surmise common reduced gamma amplitudes underlying both onset and offset of sevoflurane in the no-response as compared to response spectra, supporting this parallelism.

\section{Synergism of cortical and subcortical sedative effects}

General anaesthetics act directly on prefrontal cortex (Deshpande et al., 2010). Sedative doses also reduce brainstem monoaminergic activity (Lu et al., 2008), and this effect is enhanced by opioids (Cox et al., 1998). Propofol directly inhibits M1, but not M2 muscarinic 
transduction and enflurane inhibits M1 and 5-HT2C activated currents (Lin et al., 1993; Murasaki et al., 2003). Physostigmine, a cholinesterase inhibitor, reverses propofol-induced unconscious states (Collier and Mitchell, 1967; Meuret et al., 2000). Desynchronization of the occipital EEG from eyes closed to eyes open correlates with increasing activity in the cholinergic nucleus of basalis and its engagement with visual cortex (Wan et al., 2019), by restoring the ratio of excitation to inhibition. ACh levels are much lower during anaesthesia than quiet resting, which is dominated by occipital alpha rhythms.

The idea of a reduction in overall activity of brainstem 'arousal' centres and a relative enhancement of oscillatory-inducing cholinergic $\mathrm{G}_{\mathrm{i} / \mathrm{o}}$-receptor subtype by anaesthetizing drugs is supported by the finding that the acetylcholinesterase inhibitor physostigmine increases EEG alpha power in subjects sedated by midazolam (Ebert et al., 2000). The author knows of no other theory outside of MAB that adequately addresses the twin paradoxes represented by the aforementioned study and paradoxical delta enhancement during painful stimuli discussed below. There remains a distinction however, between slow oscillations during quiet rest or sleep and compatibility of the coexistant alpha/delta spectrum with adequate depth of anaesthesia explained by direct anaesthetic effects in the next section.

\section{Consideration of molecular mechanisms of action of anaesthetics}

Theories of sedative function generally posit actions on the $\mathrm{GABA}_{\mathrm{A}}$ receptor common to many anaesthetics. A recent review can be found in (Hemmings et al., 2019). However, the field is moving rapidly and no one site seems to explain all features of anaesthetic agents. New findings on the effects of agents on $\mathrm{K}+$ channels reinforce targets outside of $\mathrm{GABA}_{\mathrm{A}}$ receptors (Pavel et al., 2020). Care must be taken not to assume the misleading, but oftrepeated category error in neuroscientific explanations, that local inhibitory effects easily translate into higher level behavioural or cognitive inhibition. It is high amplitude generalized oscillatory activity that correlates with inhibition of higher orders of function and that doesn't entail quiescent neuronal activity that GABAergic theories require i.e. it is the entire cycle of synchronous oscillations that are causal in a state-related loss of information and not the troughs that are relevant here. A theory of dual cognition provides one solution to the paradox of the putative down state of high amplitude delta during conscious awareness as seen in Angelman syndrome (Frohlich et al., 2020) and in other delta prominent states as discussed in the very useful review by (Frohlich et al., 2021). Peaks in delta rhythms do not code any useful information in the context of widespread neural synchrony. By focussing in this section on targets commonly attributed to anaesthetic agents and exploring their interactions with monoamine and cholinergic neuromodulatory systems, the author hopes to address some of the uncertainty surrounding the relative contributions of these targets to a common mechanism of unconsciousness and unresponsiveness more generally.

Desynchronization of the cortical rhythm is induced by monoamine and cholinergic neuromodulation. These act by inactivating several $\mathrm{K}+$ currents, including the slow $\mathrm{Ca}+-$ activated $\mathrm{K}+$ current generating afterhyperpolarization $I_{\mathrm{AHP}}$, a voltage-dependent (depolarization-activated) $\mathrm{K}+$ current $I_{\mathrm{m}}$ and the so-called 'leak' $\mathrm{K}+$ currents at resting membrane potentials, see excellent review by (McCormick et al., 1993). Both activation of protein kinase $\mathrm{C}$ and adenylyl cyclase- and cAMP-dependent pathways are implicated. The pattern of neuronal firing from single-spike activity to burst firing that establishes an oscillatory pattern is dependent on relative neuromodulator levels. A drop inactivates the

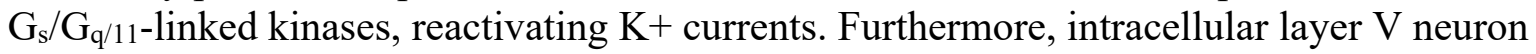
injection of sine wave currents generated repetitive burst firing at $<4 \mathrm{~Hz}$ and $8-10 \mathrm{~Hz}$, 
intriguingly along a natural cleavage that corresponds to delta and alpha spectral ranges. A fourth $\mathrm{K}+$ current, which was assumed to be G-protein linked and likely corresponds to GIRKs was activated by 5-HT1-serotonergic and GABA $\mathrm{B}_{\mathrm{B}}$ receptors. It is likely to converge with reactivation of multiple $\mathrm{K}+$ channels associated with lower modulatory neurotransmitter levels (VanDongen et al., 1988). Facilitation of $\mathrm{K}+$ currents is an elegant mechanistic explanation of a shift to hyperpolarization and concomitant generation of slow oscillatory rhythms. Pharmacologically, greater apparent affinity for $\mathrm{G}_{\mathrm{i} / \mathrm{o}}$ inhibitory over excitatory receptor effects explains emergence of slow oscillations with reduced neuromodulator activity that is associated with sedation.

The interaction between anaesthetics and neuromodulators is partly motivated by naturally occurring EEG slow oscillations during wake/sleep cycle, specifically delta and alpha, that are linked to subcortical arousal systems. The latter have been shown to modulate oscillatory rhythms in fundamental ways. However, reducing monoamine and cholinergic levels alone, although generating ubiquitous slow wave EEG rhythms, is insufficient to render an animal totally unconscious. In rats, combined use of reserpine and scopolamine individually, raise average alpha and delta power by $47 \%$ and $60 \%$, respectively (Dringenberg and Diavolitsis, 2002), but concomitant use of scopolamine ameliorates immobility caused by reserpine for the doses used (Yu et al., 2019). Anaesthetics such as propofol increase alpha and delta oscillatory power by up to 10 fold in states of unconsciousness (see figure $2 \mathrm{C}$ ). Thus, direct anaesthetic mechanisms on neural networks likely contribute to the underlying power of the slow rhythms correlating with unresponsive states.

\section{$G A B A_{A}$}

Much emphasis on an anaesthetic mechanism relies on potentiation of $\mathrm{GABA}_{\mathrm{A}}$ ligand-gated ion channels cortically (Hemmings et al., 2005) and could have direct effects on subcortical nuclei by reducing firing rates. It's become increasingly apparent that this can only be part of the story of molecular mechanisms of anaesthetic induced unconsciousness. For example, whereas a point mutation in the $\beta 3$ subunit of the $\mathrm{GABA}_{\mathrm{A}}$ receptor abolishes suppression of evoked movements by noxious stimuli and loss of righting reflex in mice by the intravenous agents propofol and etomidate, it barely altered the effectiveness of the volatile anaesthetics enflurane and halothane (Jurd et al., 2003). Inhibitory cortical interneurons that use GABA are implicated in desynchronizing cortical rhythms by enhancing the signal-to-noise ratio of sensory stimuli. There is however, an aesthetic symmetry or identity to be found in the proposal that anaesthetic action at GABAergic receptors modulate consciousness through an interaction with cholinergic and monoamine cortical projections. The presence of large populations of corticopetal GABAergic and glutamatergic subpopulations within subcortical nuclei such as the basal forebrain and brainstem raphe intermingled with cholinergic and serotonergic neurons suggest a coordinated role that may underlie naturally occurring oscillatory rhythms.

The core concept that emerges from analysing the data is that convergent $K+$ current activation triggers the burst-firing character of slow oscillation frequencies. However, the widespread cortical synchronization is facilitated by putative $G A B A_{A}$ receptor activation, postsynaptic to corticopetal projections during the natural sleep-wake cycle. This occurs onto both pyramidal and non-pyramidal cortical elements and analogously, by the direct effects of anaesthetic GABA receptor agonism. This acts to reduce the signal to noise ratio. 
Slow oscillatory burst firing can, in principle, still carry information if not entrained by a more disruptive neural synchrony ${ }^{4}$.

Cortically projecting GABAergic basal forebrain neurons are afferent to both pyramidal cells and interneurons (Henny and Jones, 2008). Both cholinergic and parvalbumin-containing GABAergic corticopetal BF neurons increase their firing rates during low voltage fast activity (Duque et al., 2000). At waking levels of cholinergic function, cortically projecting parvalbumin GABAergic neurons could play a role in synchronizing neural activity with an increase in the signal to noise ratio. This was illustrated by an optogenetic study stimulating basal forebrain parvalbumin neurons entraining a cortical oscillator with a resonant frequency at $40 \mathrm{~Hz}$ augmenting gamma band oscillatory amplitude (Kim et al., 2015). Importantly, it wasn't simply driving the cortical EEG. Whether the amplitude of the alpha spectral frequency is similarly entrained by GABAergic input remains to be investigated. Parvalbumin neurons discharged at higher rates during wakefulness and REM sleep in the aforementioned study. It is plausible that as the neuromodulator environment changes, occipital alpha at quiet rest with eyes closed for example, might be associated with a corresponding GABAergic activity firing at a corresponding harmonic. This would serve to further synchronize and increase the amplitude of the alpha oscillation. By extrapolation, a similar role can be proposed for medial septal GABAergic neurons projecting to the hippocampus and the theta band power increases seen with volatile anaesthetics (Hagihira, 2015).

\section{Potassium channels}

A promising avenue of research in anaesthetic effects on slow oscillations is suggested by the proposed theoretical model of GIRK channel activation by $\mathrm{G}_{\mathrm{i} / \mathrm{o}}$-coupled receptors and the potential enhancement by confluent non-GIRK $\mathrm{K}^{+}$-hyperpolarizing currents. Most anaesthetics appear to have a limited role in receptor GIRKs themselves (Li et al., 2018). Volatile, but not intravenous general anaesthetics, directly potentiate the outwardly-rectifying two-pore-domain $\mathrm{K}^{+}$channels, however (Patel et al., 1999). These include TREK-1 and to a more limited extent TASK hyperpolarizing voltage-independent 'leak' channels. Trek1 $1^{-/}$ knockout mice show resistance to volatile anaesthesia (Heurteaux et al., 2004). Thus, an indirect mechanism of potentiating $\mathrm{G}_{\mathrm{i} / \mathrm{o}}$-mediated $\mathrm{K}+$ currents would in part account for the hyperpolarizing effects of volatile anaesthetics. More importantly, a recent study found that TREK-1 is activated by phospholipase D2 (PLD2) and is released from lipid rafts disrupted by anaesthetics. At least in flies, this is an indirect mechanism of action of other classes of anaesthetic including propofol and is consistent with null mutation (PLD $\left.{ }^{\text {null }}\right)$ flies showing resistance to anaesthesia (Pavel et al., 2020). The findings of an indirect activation of $\mathrm{K}+$ as a generalizable feature of anaesthetics is compelling.

A further hypothesis about selectivity of oscillatory synchronizing frequency bands requires converging modulation of neural networks by either hyperpolarizing muscarinic or monoaminergic transduction to the anaesthetic effects. Anaesthetics activate two pore domain $\mathrm{K}+$ channels changing resting membrane potential, as they are not voltage gated (O'Connell et al., 2002; Suh and Hille, 2005). In theory, sedating agents thus potentiate the hyperpolarizing effects of neuromodulators at GIRK channels in addition to reactivation of several other $\mathrm{K}+$ channels, as described. Critically, this is coupled with a general decrease in neuromodulator activity at $\mathrm{G}_{\mathrm{q} / 11}$ receptors (due to general reduction in firing of cholinergic

\footnotetext{
${ }^{4}$ This doesn't require exlusively precise interareal phasic coherence.
} 
and monoaminergic nuclei), which in turn sustains levels of $\mathrm{PIP}_{2}$ (phosphatidylinositol biphosphate). $\mathrm{PIP}_{2}$ is required for GIRK activity (in addition to $\mathrm{G}_{\beta \gamma}$ mediated signalling transduction of $\mathrm{G}_{\mathrm{i} / \mathrm{o}}$ receptor activation) and PLC (phospholipase $\mathrm{C}$ ) sequestration of the phosphoinositide depletes its activity. One has, at least in principle, a mechanistic solution to oscillatory activity of typical anaesthetic bandwidths.

The potential importance of $\mathrm{K}+$ channels in the generation of delta rhythms is exemplified by the neurodevelopmental disorder Angelman syndrome, where disruptions of ubiquitin protein ligase (UBE3A) augments calcium voltage dependent big potassium channels (Sun et al., 2019). High amplitude delta waves are a characteristic EEG feature and conscious awareness is typically preserved. There is, conversely, some specificity here with no augmentation of alpha or spindle oscillations that one might expect to mimic unconscious anaesthetic states. Exactly why $\mathrm{G}_{\mathrm{i} / \mathrm{o}}$-linked receptors induce a characteristic oscillatory frequency depending on the neuromodulator in question is an outstanding question, but could be resolved empirically. However, the principle of anaesthetic actions rests on an agent's ability to entrain neuromodulatory generation of distinct spectrums, alpha or delta, by way of amplitude augmentation.

\section{$G A B A_{B}$}

The role of the $\mathrm{GABA}_{\mathrm{B}}$ receptor for the sedative effects of anaesthetics has received scant attention. Halothane uniquely increases basal GIRK currents but inhibits M2 muscarinic receptor-coupled activation at low anaesthetic concentration (Weigl and Schreibmayer, 2001). This blocking effect is overcome at higher doses of halothane by facilitating association of $\mathrm{G}_{\beta / \gamma}$. However, there is evidence that $\mathrm{GABA}_{\mathrm{B}}$ receptors are a target for general anaesthetics mediating at least in part, their hypnotic effects. GABA ${ }_{B}$ agonists also increase delta power during SWS (Black et al., 2014). GABA $\mathrm{B}$ receptors are coupled to GIRKs and two-pore domain potassium channels in the rat neocortical layer 5 and hippocampal CA1 pyramidal neurons (Breton and Stuart, 2017). GIRKs are considered the receptor's predominant signalling pathway. So, both the $\mathrm{GABA}_{\mathrm{A}}$ agonist muscimol and the potent $\mathrm{GABA}_{\mathrm{B}}$ agonist baclofen behave in a synergistic manner to potentiate the effects of sevoflurane on the CA1 area of the hippocampus and phaclofen, a GABA $\mathrm{B}_{\mathrm{B}}$ antagonist, and the $\mathrm{GABA}_{A}$ antagonist bicuculline mitigate this effect (Hirota and Roth, 1997). Similar effects were noted in vivo for both volatile (halothane, isoflurane) and intravenous (thiamylal) anaesthetics (Sugimura et al., 2002) and propofol on cerebellar slices (Xuan et al., 2018). Non-GABAergic mechanisms of action were also implicated.

The barbiturate pentobarbital acts on both $\mathrm{GABA}_{\mathrm{A}}$ and $\mathrm{GABA}_{\mathrm{B}}$ receptors in a rat tolerance and dependence model (Kimura et al., 1991). The decreased firing of nigral dopamine neurons by propofol appears to be mediated by $\mathrm{GABA}_{\mathrm{B}}$, but not $\mathrm{GABA}_{\mathrm{A}}$, receptors (Schwieler et al., 2003). Microinjection of baclofen into the ventral tegmental area (VTA) reduced the self-administration of propofol in rats (Yang et al., 2011). Halothane causes significant reductions in $\mathrm{ACh}$ release and this is mooted to occur through $\mathrm{GABA}_{\mathrm{B}}$ receptors (Bowery, 1993). Baclofen dramatically increases the power of synchronized slow waves in rats during NREM sleep in the 1.5-6.5 and 9.5-21.5 frequency bands (Hodor et al., 2015), which includes delta and alpha, but also beta and theta and overlaps with the potentiated effects on the EEG by general anaesthetics. However, GABA modulates thalamic spindles (Ulrich et al., 2018), consistent with the idea of a convergent non-GABA, ACh muscarinic receptor-related generation of spindles. 


\section{Opioids}

Opioids are often used to supplement general anaesthesia believed to reduce arousal to noxious stimuli such as during surgical procedures by direct actions on the spinal cord. A major pathway of action of the opioid receptors is $\mathrm{G}_{\beta \gamma}$ activation of GIRKs (Al-Hasani and Bruchas, 2011) that might act through confluent pathways on the brain to enhance slow rhythms. Fentanyl in humans causes high voltage delta waves and alfentanil in dogs induces in addition high alpha at the peak of delta waves during surgical levels of anaesthesia (figure 5) (Sebel et al., 1981; Wauquier et al., 1988).

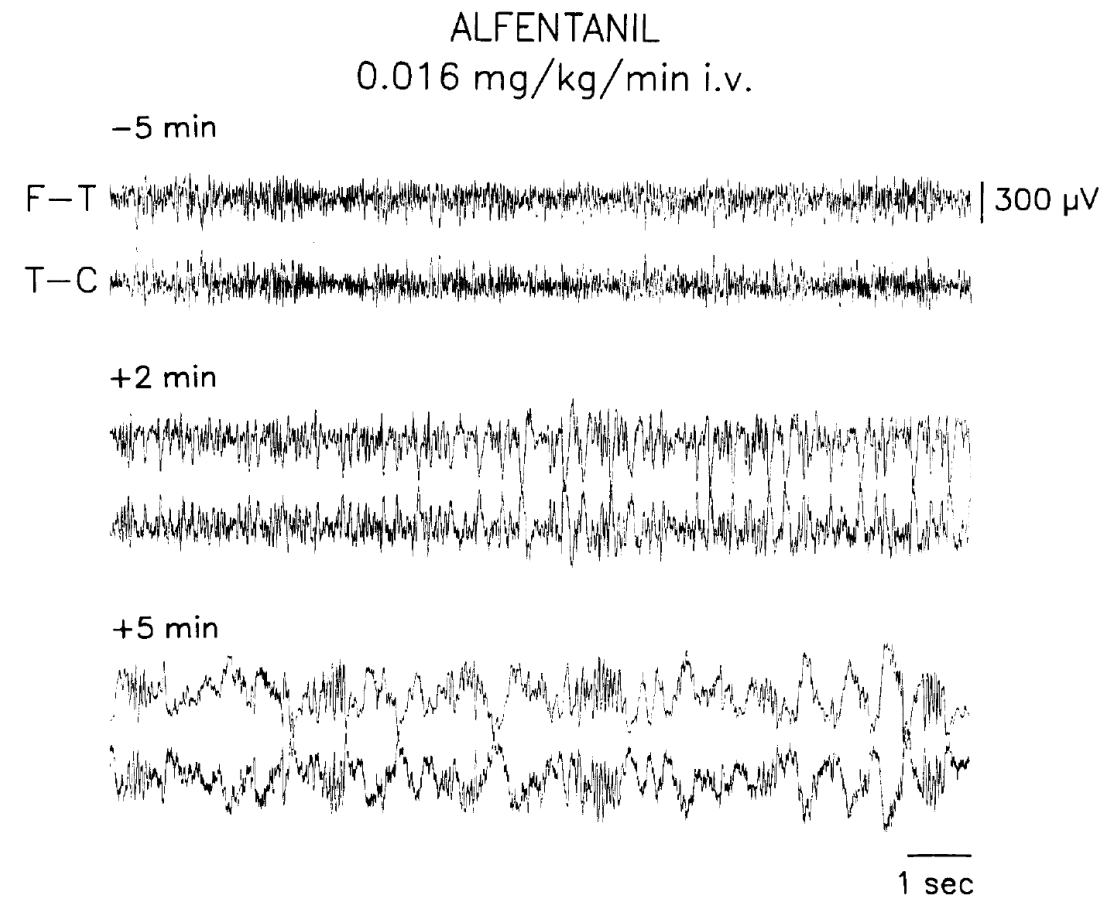

Figure 5. Neocortical EEG activity (FT, fronto-temporal; TC, temporo-central) in a dog at $5 \mathrm{~min}$ before ( = baseline), and 2 and $5 \mathrm{~min}$ after onset of a constant i.v. infusion of $0.016 \mathrm{mg} / \mathrm{kg} / \mathrm{min}$ alfentanil. Within $2 \mathrm{~min}$, baseline low voltage high frequency activity (20-25 Hz, 50-350 \#V) gradually changed into high voltage, slow waves, which, 3 min later, were replaced by the typical pattern of delta waves $(1-3 \mathrm{~Hz}, 350-650 \mathrm{HV}, 1-2 \mathrm{sec})$ mixed with bouts of faster activity $(14-15 \mathrm{~Hz}$, $50-450 \mathrm{gV}, 300-700 \mathrm{msec}$ ). Small amplitude (30-75 gV) activity in the alpha and beta frequency ranges rode on top of delta activity. Permission (Wauquier et al., 1988).

\section{Further implications of the model}

The strength of the MAB model is that it can integrate anomalies of general anaesthetics, including various unrelated pharmacological actions into a unitary theory. It can also explain amnesia in both sedative and hypnotic contexts even when there is no loss of consciousness.

\section{Types of amnesia and evidence from sleep}

There is a strong tradition for studies exploring the interactions between monoaminergic and cholinergic neurotransmitters in animal memory models (Altman et al., 1989; Decker and Gallagher, 1987; Isaacson et al., 1986; Richter-Levin and Segal, 1989; Riekkinen et al., 1991) 
and has been the motivation behind a theoretical paper detailing the roles of individual neuromodulators. Broadly, the theory posits inverse selective effects on declarative versus procedural memories (Vakalopoulos, 2006). Support for a direct role of neuromodulation in human memory comes from Alzheimer's patients where there is not only deficient cholinergic function but a more recent emphasis on an early loss of monoaminergic brainstem neurons (Grinberg et al., 2009; Mesulam, 2013; Rüb et al., 2000; Yamamoto and Hirano, 1985). In Alzheimer's disease alpha power is markedly reduced with a concomitant increase in delta sources (Prichep et al., 1994). The EEG changes are not well correlated with gray matter volume loss (Babiloni et al., 2013). The findings are consistent with relative cholinergic to monoaminergic loss.

Some of the best evidence for a direct causal role of neuromodulation occurs during sleep. Explicit memories are consolidated during SWS, when monoaminergic levels are increased relative to ACh (Gais and Born, 2004a, 2004b; Plihal and Born, 1997). Although absolute levels of both neuromodulators are decreased, ACh concentration is the lowest for the entire sleep-wake cycle. SWS is marked by prominent delta rhythms. Conversely REM sleep occurs when monoamines, dopamine excepted, are at their lowest and $\mathrm{ACh}$ is at waking levels. REM sleep is considered important for procedural or implicit memory consolidation (Hars et al., 1985; Karni et al., 1994). During waking phasic increases in activation of neuromodulators mediated by hippocampal theta is a proposed mechanism of initial memory encoding (Vakalopoulos, 2006) ${ }^{5}$. The proposal is for an anaesthetic impairment in signalling through excitatory coupled receptors coding memory traces. Disruption of phasic activity under lighter sedation and thus, memory of events, is potentially dissociated from concurrent awareness.

The use of GABA receptor agonist sedative benzodiazepines causes memory deficits of explicitly recalled word lists and a relative sparing of implicitly or semantically related cued paired words (Coenen and van Luijtelaar, 1997; Weingartner et al., 1993). Some studies suggest facilitation of learned paired associates by sedatives. In the case of the selective agent zolpidem retrieval of cued words was correlated with an increase in sleep spindle density during SWS (Mednick et al., 2013). The latter assumes a familiarity based strategy associated with spindles. SWS is involved in remodelling automatic or prepotent behaviours encoded in the interactions between processes coincident with alternating periods of spindles and delta waves. Further consolidation of implicit traces would normally be associated with REM sleep (see Appendix B).

Other tasks that may benefit from implicit learning and showed no enhancement (motor sequence task) or worsening performance (visual texture discrimination) (Mednick et al., 2013) may be explained by a requirement of REM sleep consolidation (Stickgold et al., 2002). Zolpidem reduced REM sleep. General and specific deficits and enhancements can be explained by global reduction of corticopetal monoaminergic and cholinergic activation on the one hand, and relative dynamic imbalance of postsynaptic neuromodulatory effect during particular phases of sleep or under sedative influence. It will depend on the strategies used for learning and which phases of sleep are critical to consolidation in any particular task. Thus the prediction is that sedatives have a deleterious effect on monoaminergic 'explicit' encoding and relative sparing of cholinergic 'implicit' encoding in these studies. The dual

\footnotetext{
${ }^{5}$ Descriptions of hippocampal theta were best correlated to behaviours in rat models. Theta doesn't quite have the same privileged position in primates with beta and gamma being quite prominent outside of early-stage sleep (Talakoub et al., 2019). The idea is the same, in principle however i.e. of active engagement of monoaminergic nuclei by recurrent hippocampal activity entrained by the dentate gyrus.
} 
theory of memory is important when addressing effects of anaesthetics more generally and concerning instances of retention of information under assumed unconscious conditions.

\section{Atypical agents}

Dexmedetomidine is a sedative and a highly selective $\alpha_{2}$-adrenoreceptor agonist. Etomidate also has agonist properties at this receptor site. During the unconscious state it produces spindles that are longer than in stage 2 sleep (Huupponen et al., 2008) and a more general increase in power across the slow frequency range from $2-15 \mathrm{~Hz}$ (Akeju et al., 2014), although not as high as in propofol-induced anaesthesia (Xi et al., 2018) (figure 6).

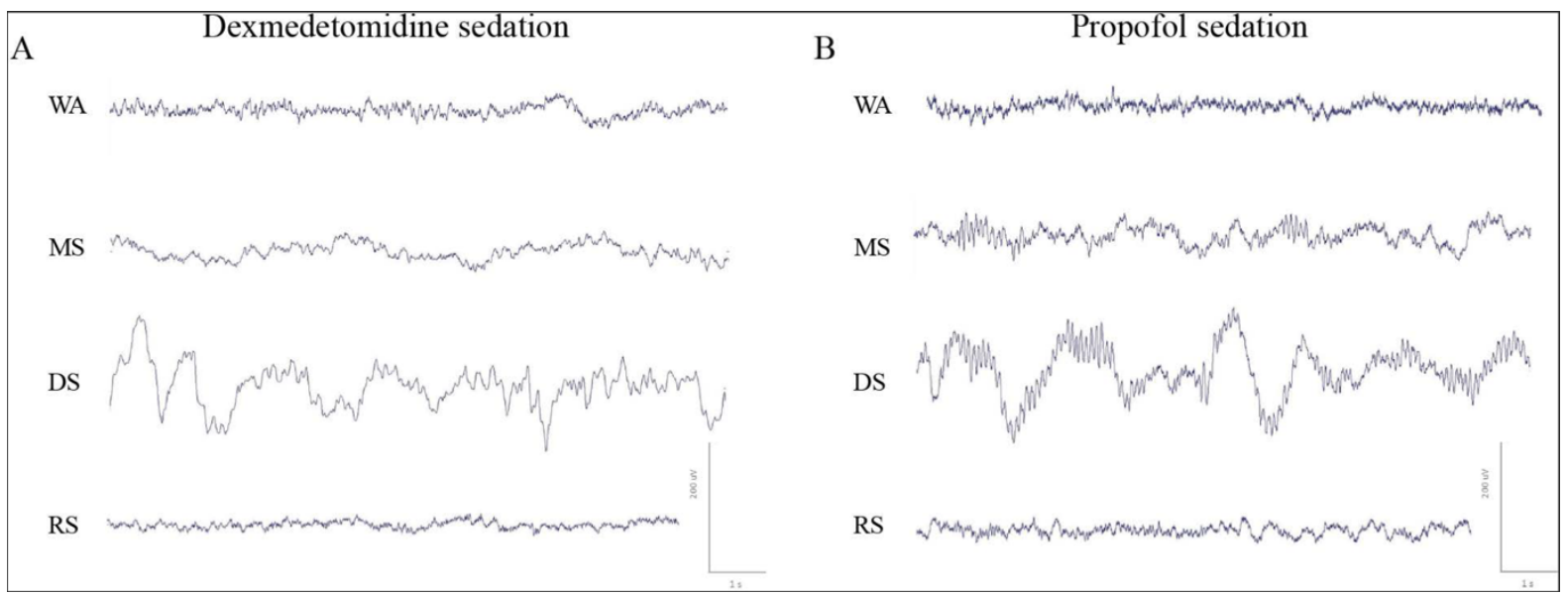

Figure 6. Changes in a raw EEG trace of dexmedetomidine sedation and propofol sedation from channel Fz. WA, wakefulness; MS, moderate sedation; DS, deep sedation; RS, recovery state (RS). During MS and DS, the EEG differences between the two agents are obvious.

Presynaptic inhibition of the locus coeruleus would reduce noradrenergic monoamine levels and thus, would augment alpha spindles by facilitating muscarinic M2-receptor $\mathrm{G}_{\mathrm{i} / \mathrm{o}^{-}}$ oscillatory activity. Additionally, direct cortical effects of NA at $\alpha 2$ receptors would according to MAB, suppress muscarinic M1-receptor mediated gamma desynchronization inducing a delta rhythm. Lower alpha power and the finding that patients are more arousable compared to other agents are accounted for by the single monoaminergic receptor class being targeted and perhaps the instability of this mechanism.

During ketamine anaesthesia-induced unconscious states an atypical spectrographic pattern presents itself with a shift from $\alpha$ spindles to $\beta / \gamma$ rhythms (figure 7) (Akeju et al., 2016). 


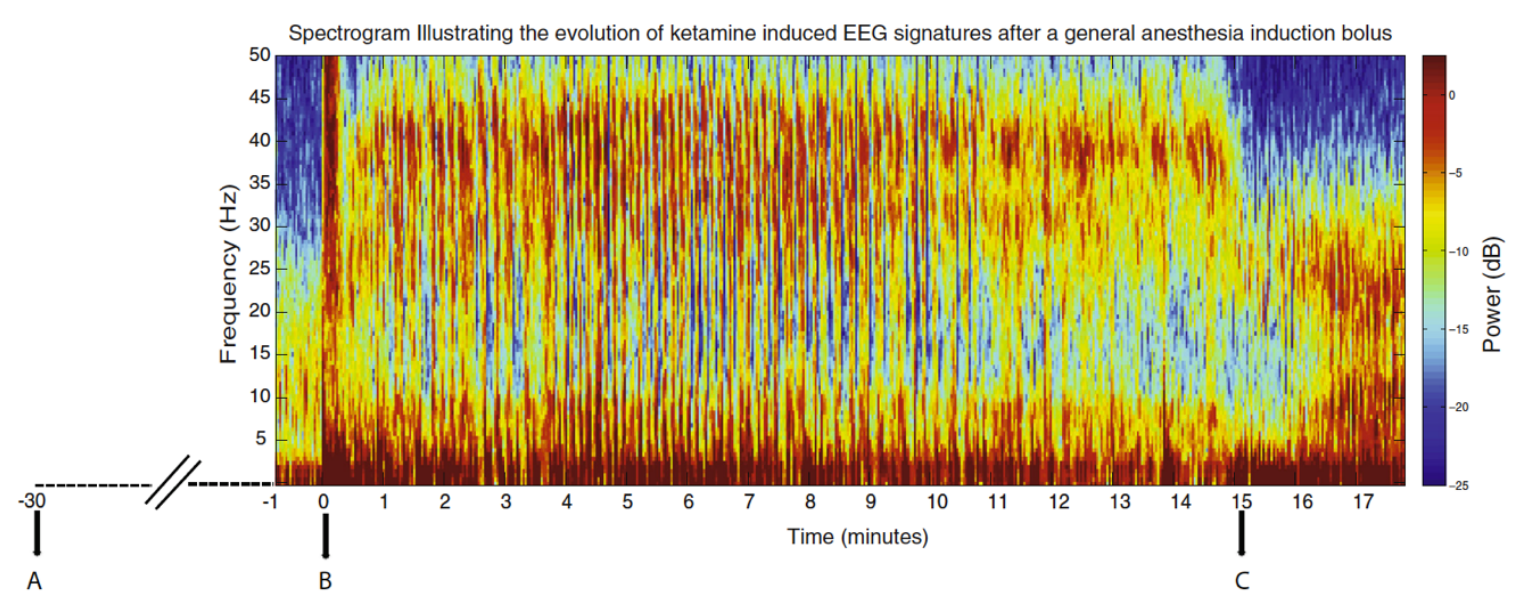

Figure 7. Illustrative spectrogram showing the evolution of ketamine anesthesia

electroencephalogram signatures. At time point A, $2 \mathrm{mg}$ of midazolam and $100 \mathrm{mcg}$ of fentanyl were administered. At time point B, $200 \mathrm{mg}$ of ketamine was administered to induce general anesthesia. Muscle artifact (solid red band encompassing $0-50 \mathrm{~Hz}$ ) can be noted at this time point. Between timepoints $\mathrm{B}$ and $\mathrm{C}$, the gamma burst and the beta/gamma patterns can both be observed. At time point $\mathrm{C}$, the anesthetic vapor isoflurane was administered to maintain surgical unconsciousness. Upon the administration of isoflurane, the beta/gamma pattern transitioned into an EEG pattern encountered when modern day derivatives of ether (desflurane, isoflurane, sevoflurane) are administered concurrently with ketamine (markedly increased slow, delta, theta, and alpha/beta power). $\mathrm{dB}=$ decibel; EEG = electroencephalogram; $\mathrm{Hz}=$ hertz.

Noxious stimulation during combined isoflurane/nitrous oxide anaesthesia can result in paradoxical arousal: increase in $\delta$ and decrease in $\alpha$ spindles (Kochs et al., 1994). Also see an EEG of paradoxical arousal with propofol and fentanyl in (Bennett et al., 2009). Both ketamine and nitrous oxide are NMDA antagonists and indirectly affect M1-type muscarinic receptor (convergent signalling due to colocalization) (Monteiro Moreira et al., 2005). NMDA increases activity of neurons in the nucleus basalis of Meynert (Manfridi et al., 1999) and M3 muscarinic receptors are found on cholinergic cell bodies in subcortical regions including the septal nucleus (Rouse and Levey, 1996). Reducing cholinergic function simultaneously augments delta power and faster frequencies by altering MAB in parallel networks. Consistent with the hypothesis of converging muscarinic and NMDA signalling pathways is the finding that delirium (a troublesome side effect of anticholinergic use) during the immediate period post anaesthetic is correlated with an emergence trajectory lacking alpha spindle power (presumed hypocholinergic state), particularly in cases where ketamine or nitrous oxide is used (Hesse et al., 2019). Further, preserved or even enhanced monoaminergic activity would suggest a potential for conscious arousal in some form. In one study, subjects reported long vivid dreams after emergence that were not related to the external environment after ketamine, while reporting no conscious experience after propofol or xenon anaesthesia (Sarasso et al., 2015).

Noxious stimuli increase brainstem monoaminergic activity in the context of constrained muscarinic signal transduction (a combined effect of NMDA antagonism and direct hyperpolarization of general anaesthetics) eliciting higher delta power. Analogously, endotracheal intubation, the case demonstrated in the figure by (Bennett et al., 2009), also induces anaesthesia-related increases in the firing rates of subcortical arousal nuclei, but augmenting $\mathrm{G}_{\mathrm{i} / \mathrm{o}}$ signalling preferentially due to direct anaesthetic actions biased towards hyperpolarizing $\mathrm{K}+$ currents. 'Paradoxical arousal' is a misnomer then for selectively 
facilitated signal transduction limited to inhibitory subtypes that generate slow oscillatory rhythms. Conversely, ketamine may mitigate arousing effects associated with painful stimuli reducing the probability of arousal.

\section{Age-related EEG changes}

Although, EEG shows qualitative similarities in an ageing cohort to propofol and sevoflurane, showing both prominent alpha and slow delta waveforms, there is a general reduction in power at all frequencies (Purdon et al., 2015). There is however a relative decrease specifically in alpha power (figure 8) and this would correlate with reduced cholinergic reserve as one would expect in elderly subjects and predicted by MAB.
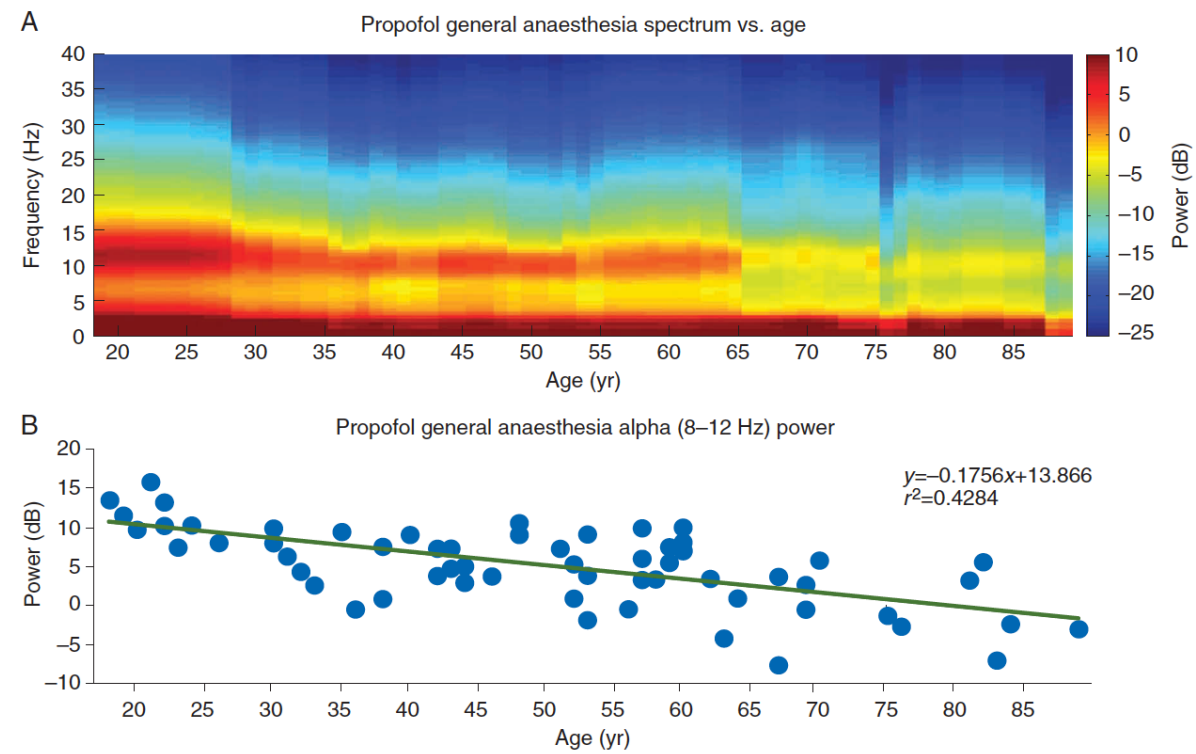

Figure 8. Trends in the spectrum and coherence from 18 to $90 \mathrm{yr}$ old during propofol anaesthesia. (A) The frontal EEG spectrum as a function of age. Slow $(0.1-1 \mathrm{~Hz})$ oscillations are present in all patients during general anaesthesia maintained solely with propofol. Alpha $(8-12 \mathrm{~Hz})$ oscillations appear to diminish with age. (B) The trend in alpha power appears to decrease with age. The green line represents a linear regression model describing the relationship between age and alpha power.

Burst suppression increases significantly with age. Burst suppression as a correlate of unconsciousness is, in a sense, the trivial condition of anaesthetic action where there is an induced profound suppression of presumed reduced reserve capacity in the brainstem and basal forebrain. The MAB model of EEG reduced alpha power also provides insights into the increased risk of delirium in the elderly patients with pronounced intraoperative anticholinergic effects. Burst suppression is a state of deep brain inactivation and susceptibility increases with age correlating with low frontal alpha power (Shao et al., 2020). However, considerable variability is present between individuals implicating other pharmacodynamic factors. A relative cholinergic deficit can accommodate both ageing decreases in alpha and propensity to burst suppression and non-age related interindividual variability, where there is a putative profound anaesthetic sensitivity in reducing firing of the basal forebrain. The latter implies that a small healthy or younger subset of patients might not manifest typical frontal alpha patterns during adequate anaesthesia. This does not negate the 
association of the unconscious state with spindle alpha, because ultimately alpha is only a signal of suppressed phenomenological behaviour. It is not the sufficient and necessary correlate of an unconscious state in every individual, or even in any individual with a deep enough sedative dose, but is a useful corollary of an unconscious state when present.

\section{Evidence from coma and epilepsy patients}

\section{Coma}

One of the first papers to demonstrate what was to become defined as alpha coma was a case study of a brainstem haemorrhage of the central pons extending to the caudal mesencephalon (Loeb and Poggio, 1953). The patient displayed an EEG at 10-12 Hz without any underlying delta rhythm. Soon others noted a conspicuous EEG 'wakefulness' pattern in brainstem coma patients often in the slower alpha range (Chatrian et al., 1964; Hauge et al., 1956). Unlike quiet rest-related occipital alpha however, there is an alpha anteriorization (Tomassen and Kamphuisen, 1986). Centro-parietal regions are often implicated (Hayashi et al., 1996), which would overlap with regions (including fronto-parietal) purported to be neural correlates of conscious activity (Hayashi et al., 1996). The importance of the specificity of the pontomesencephalic lesion was confirmed early on in animal studies (Lindsley et al., 1949).

Brainstem infarcts affect monoaminergic corticopetal efferents, sparing basal forebrain cholinergic projections. That destruction of monoaminergic pathways is key to understanding alpha coma is supported by higher brainstem lesions centred in the midbrain that involves the rostral serotonergic raphe. Such a case of haemorrhage manifested spindle coma i.e. in the upper alpha low beta range (Britt et al., 1980). Upper brainstem lesions imply more complete monoaminergic lesions and thus, faster alpha rhythms putatively associated with increased cholinergic drive. Brainstem lesions do however, involve the cholinergic pedunculopontine and laterodorsal tegmental nuclei and glutamatergic inputs to the basal forebrain from the pre-coeruleus and parabrachial nucleus (Walter et al., 2018). This can explain the waning of alpha over time and the deepening of the coma with slow oscillations in subjects with poor prognostic outcomes. As has already been seen, chemical lesions of the basal forebrain in animals increases delta power (Kaur et al., 2008), an inverse relation of MAB.

Brainstem infarcts resulting in alpha or spindle coma have its corollaries in neurophysiological findings of anaesthesia. Apart from rhythms other analogous features are present including EEG change to beta activity preceded recovery of consciousness in a post drug ingestion coma case a day later (Grindal et al., 1977). Further, painful stimulation in a case of locked-in syndrome-related pontine infarct caused a change in the EEG reminiscent of paradoxical arousal during anaesthesia (figure 9). In this instance painful stimulation increases residual monoaminergic activity, as predicted for the situation in anaesthesia, eliciting conscious signs in the locked-in state. Of course depending on the severity and anatomical localization of the lesion, auditory or painful stimuli can alternatively increase 


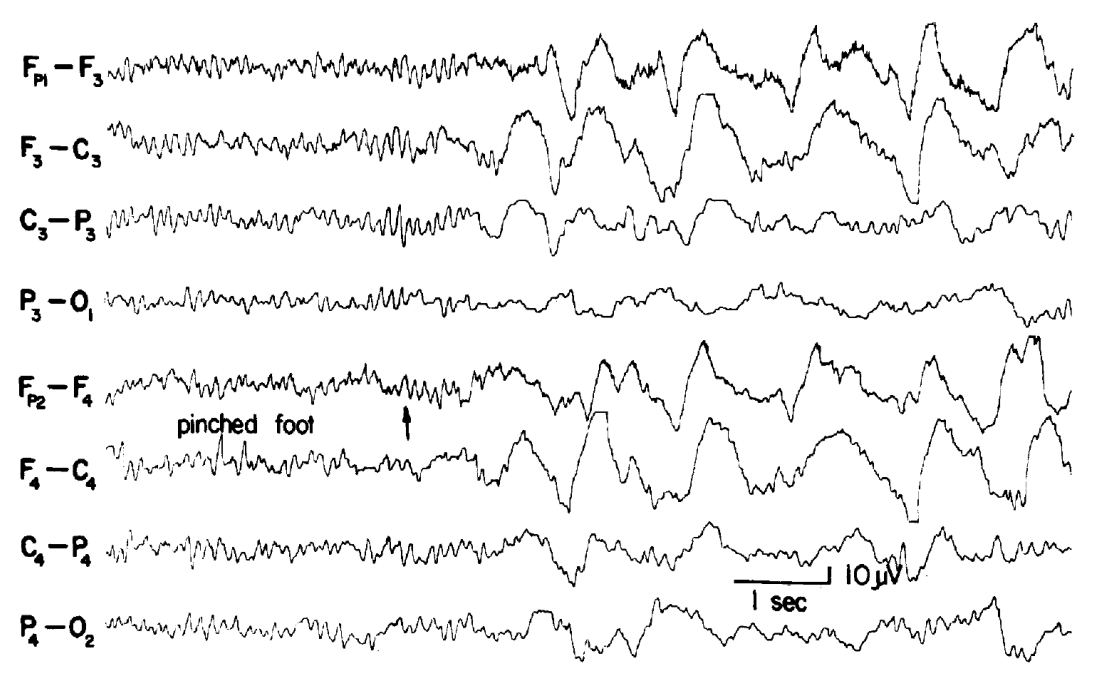

Figure 9. Predominant frontal slowing following painful stimulation (Grindal et al., 1977).

diffuse alpha power, as in another description of a pontine infarct (Tomassen and Kamphuisen, 1986) i.e. enhanced cholinergic drive without concomitant increase in monoaminergic levels due to specific disruption. Dynamic changes in the EEG of coma patients during sleep-wake cycle (Westmoreland et al., 1975) and in response to sensory stimuli support subtle changes in monoamine-cholinergic muscarinic balance i.e. subtle in the sense that they may not restore conscious function (see figure 6 in this reference).

The brainstem cases of alpha coma gives strong circumstantial evidence for the direct or indirect role of neuromodulatory cortical projections in anaesthetic hypnotic mechanisms and for direct GABAergic agonist properties on subcortical nuclei. Later studies showed that alpha coma wasn't exclusively related to brainstem pathology but many cases resulting from diffuse cerebral anoxia with greater sparing of the brainstem (Westmoreland et al., 1975). It is plausible that there is a relative sparing of cholinergic cortical fibres/terminals compared to monoaminergic in these instances. On the other hand high voltage delta activity associated with extensive structural abnormalities of subcortical white matter (Sutter and Kaplan, 2012) destroys both monoaminergic and cholinergic corticopetal fibre tracts.

\section{Epilepsy}

Focal temporal lobe or complex partial seizures associated with large increases in theta to beta range of activity often puzzlingly impair consciousness. One proposal is for indirect subcortical effects on frontoparietal networks generating cortical 1-2 Hz slow waves (Englot et al., 2010). The authors speculated that unconsciousness results from ictal neocortical slow activity and not the outward spread of fast temporal lobe discharges. The opinion was based on another study in rats showing that transection of the fornix prevented the cortical and behavioural effects of hippocampal-induced seizures (Englot et al., 2009). Temporal lobe seizures increase blood flow to the upper brainstem (Lee et al., 2002). These findings are consistent with a hypothesis of hippocampal rhythmicity leading to phasic increases in midbrain and pontine monoaminergic activity (Vakalopoulos, 2006). The MAB imbalance is pathologically accentuated by epileptically induced hippocampal oscillations and its effects on monoamine levels in the brain. A pilocarpine animal model of status epilepticus in rats resulted in a marked acute increase in hippocampal 5-HT levels. The generation of seizure 
activity was not thought to be due to direct effects on the medial temporal lobe (Lin et al., 2013). Pilocarpine is a muscarinic cholinergic agonist. Various causal hypotheses were proposed, but an indirectly mediated increase in the firing rate of raphe neurons generated by a synchronous limbic output to the midbrain is a plausible mechanism.

The rat pilocarpine model of generalized seizures produces orbitofrontal polyspike activity that's maximal in the alpha frequency range (Englot et al., 2008). This is consistent with proposed direct cholinergic effects. Complex partial seizures, on the other hand, are often associated with automaton-like movements and complex behavioural outputs suggesting that delta oscillations aren't analogous to deep anaesthesia but bear some resemblance to catatonic states. Ketamine also increases delta and may act similarly in impairing cognitive states. This is supported by the prevalence of psychosis in about $10 \%$ of cases of temporal lobe epilepsy (Irwin and Fortune, 2014) and a presumptive enhancement of cortical monoaminergic release as speculated above.

\section{Conclusion}

Alpha rhythms are an indirect index of encoding of implicit memory traces only, but are a direct correlate of unconsciousness when recorded from frontoparietal associative cortex. Particular theoretical emphasis is on the temporoparietal junction, which straddles both ventral and dorsal streams. There are limitations demonstrated by case studies of awareness during anaesthesia using BIS and most monitors do not show explicit quantification of alpha power. It remains difficult to detect small changes in alpha power with the raw EEG signal. The spectrogram is a good alternative for monitoring alpha and should be considered for routine use to monitor state of anaesthesia. PCI can be used as a homologue to ERP reactivity in conjunction with the EEG. Understanding the pharmacological basis of cognition and how this is reflected in the real time EEG can add to a nuanced response to changes during surgical procedures. Further investigations are required to elucidate the underlying neurophysiology of the small number of patients where no alpha increases in power can be induced in spite of adequate hypnotic effect.

In summary, the model elegantly handles cognitive interpretations of high amplitude oscillations in the EEG under different altered states of awareness (figure 10). 


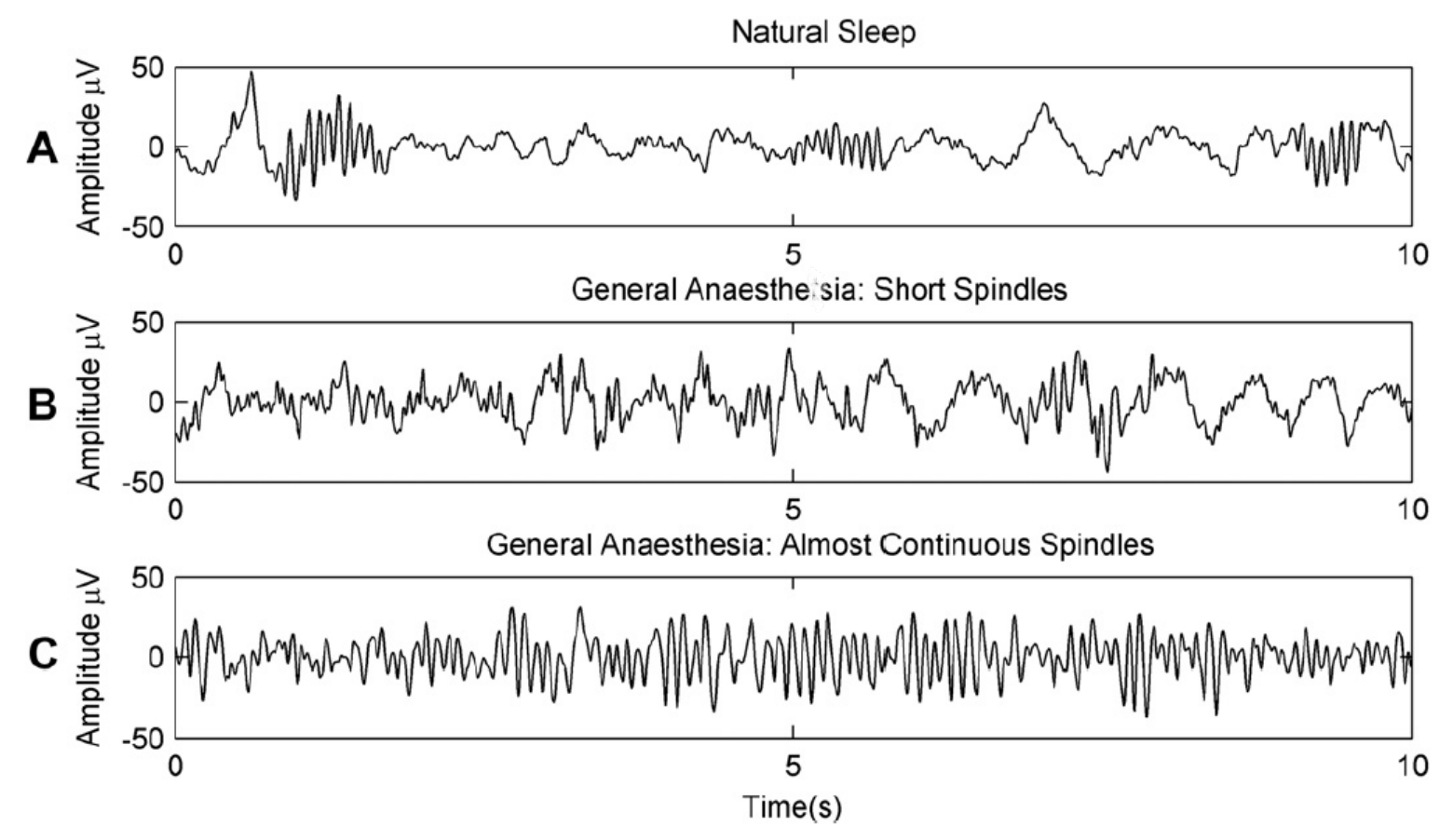

Figure 10. Examples of EEG spindles in natural sleep (A), and during general anaesthesia with desflurane and fentanyl (B and C). All were obtained using a pre-frontal electrode montage. Note the prominent background delta activity in 1A and 1B. Permission from (Sleigh et al., 2011).

A: Natural NREM sleep shows discrete periods of spindles and delta wave activity indexing pharmacological markers of alternate cognitive processes including consolidation of explicit and remodelling implicit traces. Temporal segregation of spindle and delta rhythms is permissive of parallel cognitive constructs. Procedural learning can be further consolidated during REM sleep. B: Concurrent suppression of cognitively active subconscious (delta) and conscious (spindles) processes and thus, in principle, total awareness. C: Predominant spindling is a meaningful suppression of conscious but not unconscious cognitive processing potentially allowing implicit registration of intraoperative events! It does not, of course, directly comment on peripheral processing or reflex ability to respond although these are likely affected by paralysis and anaesthetic effects.

Finally, waking up post operatively is associated with an acute increase in high frequency activity (figure 11). The model suggests that this is due to release from oscillatory hyperpolarizing GIRK-induced spindle activity on the neural correlate of awareness and restoration of excitation/inhibition balanced transduction associated with high levels of neuromodulators. 


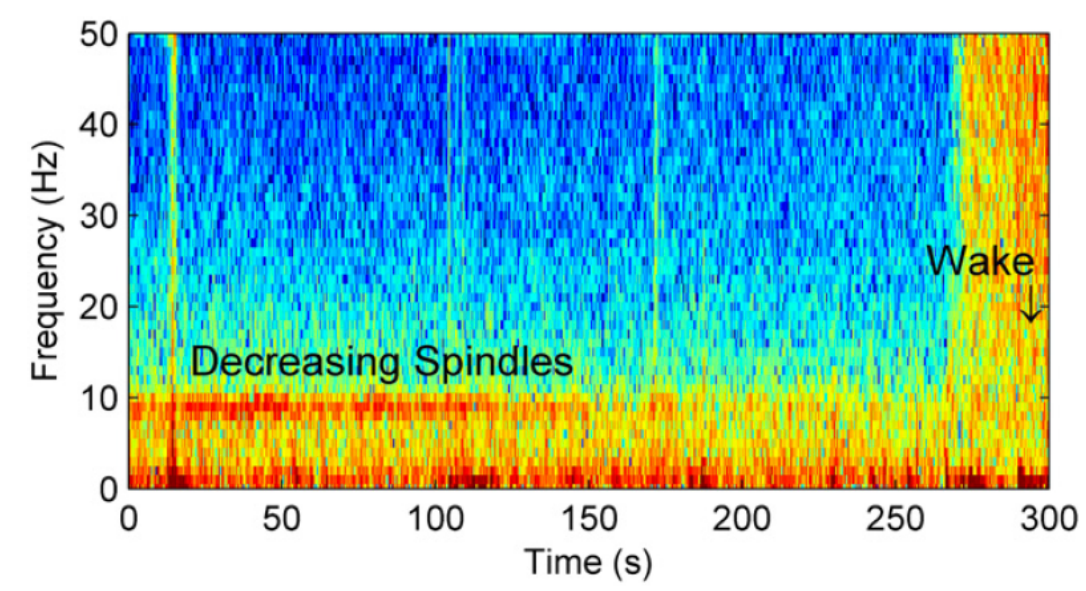

Figure 11. Example of an EEG spectrogram around the end of an operation under desflurane and remifentanil. At the left of the diagram (from 0 to $150 \mathrm{sec}$ ) a decrease in volatile anaesthetic concentration results in an obvious decrease in the spindle activity (peak frequency $9.5 \mathrm{~Hz}$ ). At 260 sec the patient shows a sudden increase in high frequencies, consistent with return of EMG tone, but does not start responding to verbal command until the $290 \mathrm{sec}$ mark. Permission from (Sleigh et al., 2011). Of potential interest here is the relative decrement in alpha spindling compared to delta.

\section{Appendix A: Disorders of Consciousness}

Much speculation exists surrounding preserved 'pockets' of consciousness during minimally conscious and vegetative states (MCS, VS) and especially in relation to ethical concerns about withdrawal of life support. Definitive statements on physiological markers of awareness remains uncertain and multiple processes are needed when assessing the likelihood of conscious preservation. This includes removing ambiguity through cognitive task-related neuroimaging (Owen et al., 2006). Interpreting the EEG however, can make certain predictions about the relative integrity of ascending reticular activating system (ARAS) and basal forebrain. The ARAS has figured prominently since the earliest theories of brainstem dysfunction during disorders of consciousness (Lindsley et al., 1949). Moreover, an EEG index of pharmacological markers can complement global metabolic measures, which are not exclusively associated with conscious states (Boveroux et al., 2008). A critical feature of the EEG from VS and MCS patients is a marked reduction in alpha band activity and a corresponding increase in delta power (Chennu et al., 2014). MAB predicts relative preservation of monoaminergic as compared to cholinergic cortical activity. Persisting delta is consistent with islands of conscious awareness.

Notwithstanding the association between delta and consciousness, outliers in the VS cohort that could perform tennis imagery had better preserved alpha band connectivity (Chennu et al., 2014) suggesting retained integrity of the cholinergic basal forebrain. This is consistent with the findings that intact alpha power and reactivity have better prognostic implications (Bagnato et al., 2015). It signifies preserved dynamic neuromodulation rather than any direct association of alpha with conscious awareness. Otherwise alpha activity doesn't reliably differentiate between VS and MCS (Liberati et al., 2014). It remains likely however, that EEG markers can discriminate severity of disordered conscious states and in those studies that don't, it may simply be that inadequate clinical criteria were used (Bagnato et al., 2017; Fingelkurts et al., 2013). Baseline amplitude, frequency reactivity and change at 6 months are better indices of outcome. 
Contrary to findings in VS, lower alpha was associated with covert conscious awareness in MCS, fitting the general assumption that alpha activity is not an index of awareness per se. A study did show some spindles during NREM sleep in MCS, but not VS suggesting NREM cycle unmasks a preserved component of cholinergic function (Landsness et al., 2011). MAB states that relative disruption of basal forebrain output as compared to brainstem function in MCS and VS patients reduces alpha, but preserves consciousness. Conversely, recovery from VS correlates with increased ARAS (specifically the intralaminar thalamus) connectivity to the basal forebrain, parietal lobe and prefrontal cortex based on diffusion tensor tractography (Jang and Kwon, 2019; Jang et al., 2016). VS and MCS are common sequelae after traumatic brain injury (TBI) and human and animal studies show cortical cholinergic deficits and basal forebrain damage, which appears to be relatively selective (Arciniegas, 2003; Dewar and Graham, 1996; Donat et al., 2008; Murdoch et al., 2002; Salmond et al., 2005; Schmidt and Grady, 1995). Monoaminergic and brainstem cholinergic nuclei are often spared in TBI (Valko et al., 2016).

Studies in dementing brain disorders show a direct correlation between decline in cholinergic activity and reduced alpha. Association of reduced alpha power with degenerative changes in cholinergic white matter tracts (Babiloni et al., 2009) and poor alpha reactivity (Babiloni et al., 2010) has been demonstrated in Alzheimer patients. Lewy body dementia (LBD) is marked by early and more severe deficits in cholinergic function and corresponding loss of forebrain neurons (Francis and Perry, 2007; Perry et al., 1993; Tiraboschi et al., 2002). Indeed, in one study of patients with LBD, one third had no posterior alpha, slowing of the mean dominant rhythm overall. REM sleep behaviour disorder (where cholinergic activity is normally comparable to waking) progressed from 60 to above 90 percent of subjects on reassessment over time (Bonanni et al., 2008). These changes correspond to loss of alpha as the dominant rhythm and increased frontal intermittent rhythmic delta activity (Briel et al., 1999; van der Zande et al., 2020). Other studies show improvement on some measures of arousal by deep brain stimulation of intralaminar thalamus, including what might be considered stereotypical behaviour, bilateral hemisphere recovery of alpha rhythms and disappearance of delta waves (Hassler et al., 1969; Schiff et al., 2007). These changes can be conveniently explained by enhanced cholinergic modulation of cortical networks. The intralaminar thalamus projects to cholinergic interneurons of the striatum (Nanda et al., 2009; Smith et al., 2004b) and is part of the putative anatomical substrate of implicit cognition.

Several caveats need addressing as regards to the sensitivity and specificity during an EEG assessment of awareness after TBI, including widespread compromise of white matter tracts interconnecting cortical areas, of which coherent states are presumed important. This is amply illustrated by the finding that cortical activation in a vegetative state is often limited to primary regions and dissociated from higher-order cortices (Laureys et al., 2002). Secondly EEG slow waves are an indirect measure of preserved pharmacological mechanisms of awareness i.e. alpha and delta rhythms represent negative indices of respective conscious and subconscious processing. Gamma rhythms are a feature of disorders of consciousness (Lechinger et al., 2013) and should prefigure in any theory of covert awareness. Furthermore, conscious memory of events during behavioural unresponsiveness (Taylor et al., 2020) is contingent on reactive monoaminergic and especially serotonergic activity (through $\mathrm{G}_{\mathrm{q} / 11}$ receptors) and this in summary, is what is indirectly indexed by persistent delta activity. The paradigm is supported by enhanced explicit memory correlates with increased slow delta and reduced alpha activity during quiet rest (Brokaw et al., 2016). 


\section{Appendix B: Plasticity and Consolidation of Memories}

A number of studies support the critical role of neuromodulators in memory encoding and consolidation. Dynamic regulation of subcortical cholinergic and monoaminergic nuclei above baseline levels is confirmed by a study looking at LTP in hippocampal slices (Watabe et al., 2000). LTP was not induced individually by low doses of the $\beta$-agonist isoproterenol or cholinergic receptor agonist carbachol, but was effective when combined. Furthermore, some receptor subtypes involved in catecholaminergic and cholinergic muscarinic interactions i.e. between $\beta$-noradrenergic and muscarinic M1 receptors, are reinforcing and assist in remodelling the prepotent aversive response.

A transient increase in locus coeruleus (LC) activity during SWS occurred 2 hours postlearning of an olfactory discrimination task and also after extinction (Eschenko and Sara, 2008). This was interpreted as evidence for noradrenergic consolidation of memory. However, optogenetic stimulation of the locus coeruleus during both SWS and REM sleep reduced NREM (non REM) spindles and disrupted consolidation of a hippocampusdependent food location learning task (Swift et al., 2018). Artificial LC activation impaired both new learning and familiar task consolidation. MAB explains these findings by considering the necessity of alternating NREM spindle and noradrenergic (NA) neuromodulation as the process of remodelling. Spindling highlights implicitly learned tasks that are enhanced by cholinergic activation (unmasked by drops in monoamine activity). Noradrenergic phasic increases that terminate spindling enhance remodelling. In other words, prepotent implicit networks must first be activated for remodelling and consolidation of a highlighted network or learned procedure to occur. This interpretation of alternating neuromodulator balance fits the recurring sleep cycles between NREM and REM sleep, during which SWS becomes less prevalent later in the night and also the importance of sleep spindles and Stage 2 sleep throughout in procedural task consolidation (Smith et al., 2004a). Activation of LC during REM sleep further interfered with consolidation based on implicit or procedural measures (Swift et al., 2018). This study was unusual in not disambiguating NA increases on memory consolidation during both NREM and REM sleep. The methodology obliterated all cholinergic mediated activity during sleep and continued to maintain the plasticity potential of place fields. This interpretation is consistent with normal consolidation of a radial maze with ripple-triggered low frequency stimulation of the LC confined to SWS and mimicking activity during normal sleep (Novitskaya et al., 2016).

Engagement of the noradrenergic system is important for cognitive flexibility (Bouret and Sara, 2005). Evidence for this comes from tasks in monkeys where, after habituation associated with a reduction in NA activity, a sudden change in behavioural contingency induces phasic increases in NA activity (Aston-Jones et al., 1997). However, unlike the hypothesis that high levels of NA activity increase distractibility as a mechanism for adaptation proposed by (Bouret and Sara, 2005), MAB suggests greater parsimony of NA inhibition, not just reinforcement of cholinergically-dependent prepotent behaviours. This is more consistent with the use of drugs with pharmacological properties of catecholamines in maintaining focussed activities.

Remodelling is generally couched in terms of potentiation and depotentiation correlating to phasic expression or silencing of NA activity, respectively. However, this does not capture the full complexity of the findings. The reversal tasks in monkeys showed a shift in NA to the new target (old ignored target) well ahead of a behavioural switch and extinction of the old target response took much longer than NA depotentiation (Aston-Jones et al., 1997). In rats 
LC activity was present in the context of both the conditioning and negative predictor in an aversive paradigm, but both disappeared once the behaviour was established (Sara and Segal, 1991). This leaves room for the concept of neuromodulation by an alternative system that is related to prepotent or automatic behaviours, i.e. cholinergic, and the difficulty in remodelling these traces can lead to maladaptive behaviours.

\section{Sharp wave ripples (SWR)}

As claimed by MAB, spindles ae an indirect index of implicit cognitive events. So, what parallel signal traces might actually be highlighted during SWS that are subsequently modified by monoaminergic activity? Most spindles are temporally correlated with hippocampal sharp wave ripples, which are synchronized high gamma frequency bursts of neurons and are typically seen during NREM sleep (Siapas and Wilson, 1998). CA1 pyramidal cell activity underlies SWR and concurrent high frequency oscillations are also present in the neocortex (Khodagholy et al., 2017). Rodent hippocampal ripples are often associated with replay of place cells that were present during learning, sometimes in novel combinations suggesting not just consolidation of previously learned behaviour, but a dynamic remodelling (Joo and Frank, 2018). Noradrenergic activity suppresses SWR in an in vivo hippocampal rat study, but a rebound increase of SWR activity followed with washout (U1 Haq et al., 2012). The inhibitory and facilitatory effects are mediated by $\alpha 1$ (some activity at $\alpha 2$ ) and $\beta$ receptors, respectively. This is a classic description of a dual mode of action in the MAB model.

\section{The hippocampus as conductor and the cortex as its orchestra: a new order}

The author would like to finish here on a contentious note regarding the role of the hippocampus in memory. Graded retrograde amnesia and loss of anterograde declarative memories after hippocampal lesions led to the belief that memories were initial encoded in the hippocampus and then gradually transferred to the neocortex for consolidation, although this was supplanted by a multitrace theory with further consolidation or transformation dependent on ongoing hippocampal-neocortical interactions 28/10/2021 15:07:00. A number of technical problems and inconsistencies beset the present iterations of the model that are raised by even proponents of the theory. The most difficult issue for the so-called slow transfer of information is the great deal of variability in time from initial encoding to cortical independence, which can even occur immediately after training. A good summary of proposed processes and some of their limitations can be found in (Squire et al., 2015).

One commonly discussed idea is the correlation between hippocampal ripples and fast cortical oscillations mediating transfer of information (Khodagholy et al., 2017). However, such correlations already assume pre-existent traces and further rely on solely Hebbian mechanisms of a transfer that is ill-defined and unsupported. Furthermore, long term potentiation (LTP) in in vivo hippocampal slices use more vigorous high frequency stimulation (HFS) protocols than short infrequent bursts of SWR (30-200 msec) and late LTP requires neuromodulation (Straube et al., 2003). $\beta$-adrenoceptor agonism enhances LTP even at subthreshold HFS by recruiting translation of mRNAs (Maity et al., 2015).

A second, albeit less dominant body of work, demonstrated strong evidence for neuromodulation in consolidating initial encoding by cholinergic and monoaminergic systems (Bailey et al., 2000; McGaugh et al., 1993). These two approaches to memory were brought into parsimony by the proposition of hippocampal rhythmicity triggering phasic 
activation of corticopetal monoaminergic nuclei (Vakalopoulos, 2006). Further consolidation occurs during sleep related modulation by monoaminergic and cholinergic systems (Vakalopoulos, 2014). The relative predominance of particular neurotransmitters have distinct signatures during REM and NREM sleep. Phasic activity of neuromodulators reinforce concurrent cortical sensory activity, coactivity acting to select for synaptic strengthening. Indeed, the limbic and paralimbic structures were first conceived by this author in their roles as modulators of dual cholinergic and monoaminergic system in a more recent paper (Vakalopoulos, 2013). The model presents a more elegant solution to systems consolidation than the concept of direct transfer of information and the confounding issues of strict timing and precedent activity. The model has the advantage that it doesn't require duplicate memory traces. The hippocampus has its own unique and permanent spatial memory repository, a finding that presents another anomaly for the temporary storage theory.

The author also proposes a new and original reconception of hippocampal remodelling and consolidation of neocortical traces based on this mechanism of subcortical neuromodulation. According to this theory, the perforant pathway to the dentate gyrus and mossy projection fibres from granule cells to the CA3 hippocampal subdivision generates neuromodulator activating rhythmicity of DR and LC. Support for the standard model described above comes from work where optogenetic activation of dentate neurons evokes fear memory recall (Liu et al., 2012). The gradual fading with time of dentate engram cells and concurrent persistence in basolateral amygdala and prefrontal cortex is consistent with shifting of remote memories from the hippocampus, although the mechanism was unclear (Kitamura et al., 2017). The standard model claims that dentate engram cells are required to recall behaviour through direct projections to the cortex. The present hypothesis is antithetical i.e. the initial persistence of a dentate engram during elicited fear behaviour continues to coactivate brainstem neuromodulators, that in turn helps consolidate and remodel cortical networks. The model emphasizes engram activity by the nature of its subcortical, not cortical projections. This can be repostulated as the reverse standard model of systems consolidation with neoHebbian connotations.

Implicit and explicit traces in CA1 and surrounding subiculum are long term. They are important for autobiographical context and spatial memories are stored there. Thus, they are more immutable for highly accurate performance, but can adaptively shift to other structures (Goshen et al., 2011). Nonetheless, if the dentate is to perform flexibly with ongoing memory formation in novel contextual contingencies throughout the life of an individual, then even covert links might ultimately be supplanted. Is there evidence for this? Neurogenesis is an active area of pursuit (Lledo et al., 2006; Lucassen et al., 2020; Saxe et al., 2006), where adult granule cells establish synapses with hilar interneurons, mossy cells and CA3 pyramidal cells (Toni et al., 2008). There is evidence for adult rat neurogenesis in newly acquired trace memories (Shors et al., 2001).

\section{References}

Akeju, O., Pavone, K.J., Westover, M.B., Vazquez, R., Prerau, M.J., Harrell, P.G., Hartnack, K.E., Rhee, J., Sampson, A.L., Habeeb, K., et al. (2014). A comparison of propofol- and dexmedetomidine-induced electroencephalogram dynamics using spectral and coherence analysis. Anesthesiology 121, 978-989. 
Akeju, O., Song, A.H., Hamilos, A.E., Pavone, K.J., Flores, F.J., Brown, E.N., and Purdon, P.L. (2016). Electroencephalogram signatures of ketamine anesthesia-induced unconsciousness. Clin. Neurophysiol. Off. J. Int. Fed. Clin. Neurophysiol. 127, 2414-2422.

Aleman-Zapata, A., Morris, R.G., and Genzel, L. (2020). Fast and slow cortical high frequency oscillations for cortico-cortical and cortico-hippocampal network consolidation during NonREM sleep.

Al-Hasani, R., and Bruchas, M.R. (2011). Molecular mechanisms of opioid receptordependent signaling and behavior. Anesthesiology 115, 1363-1381.

Altman, H.J., Ogren, S.O., Berman, R.F., and Normile, H.J. (1989). The effects of pchloroamphetamine, a depletor of brain serotonin, on the performance of rats in two types of positively reinforced complex spatial discrimination tasks. Behav. Neural Biol. 52, 131144.

Andersen, P., Andersson, S.A., and Lomo, T. (1967a). Nature of thalamo-cortical relations during spontaneous barbiturate spindle activity. J. Physiol. 192, 283-307.

Andersen, P., Andersson, S.A., and Lomo, T. (1967b). Some factors involved in the thalamic control of spontaneous barbiturate spindles. J. Physiol. 192, 257-281.

Andrillon, T., Nir, Y., Staba, R.J., Ferrarelli, F., Cirelli, C., Tononi, G., and Fried, I. (2011). Sleep spindles in humans: insights from intracranial EEG and unit recordings. J. Neurosci. Off. J. Soc. Neurosci. 31, 17821-17834.

Arciniegas, D.B. (2003). The cholinergic hypothesis of cognitive impairment caused by traumatic brain injury. Curr. Psychiatry Rep. 5, 391-399.

Aston-Jones, G., and Bloom, F.E. (1981). Activity of norepinephrine-containing locus coeruleus neurons in behaving rats anticipates fluctuations in the sleep-waking cycle. J. Neurosci. Off. J. Soc. Neurosci. 1, 876-886.

Aston-Jones, G., Rajkowski, J., and Kubiak, P. (1997). Conditioned responses of monkey locus coeruleus neurons anticipate acquisition of discriminative behavior in a vigilance task. Neuroscience 80, 697-715.

Babiloni, C., Pievani, M., Vecchio, F., Geroldi, C., Eusebi, F., Fracassi, C., Fletcher, E., De Carli, C., Boccardi, M., Rossini, P.M., et al. (2009). White-matter lesions along the cholinergic tracts are related to cortical sources of EEG rhythms in amnesic mild cognitive impairment. Hum. Brain Mapp. 30, 1431-1443.

Babiloni, C., Lizio, R., Vecchio, F., Frisoni, G.B., Pievani, M., Geroldi, C., Claudia, F., Ferri, R., Lanuzza, B., and Rossini, P.M. (2010). Reactivity of cortical alpha rhythms to eye opening in mild cognitive impairment and Alzheimer's disease: an EEG study. J. Alzheimers Dis. JAD 22, 1047-1064.

Babiloni, C., Carducci, F., Lizio, R., Vecchio, F., Baglieri, A., Bernardini, S., Cavedo, E., Bozzao, A., Buttinelli, C., Esposito, F., et al. (2013). Resting state cortical electroencephalographic 
rhythms are related to gray matter volume in subjects with mild cognitive impairment and Alzheimer's disease. Hum. Brain Mapp. 34, 1427-1446.

Bagnato, S., Boccagni, C., Sant'Angelo, A., Prestandrea, C., Mazzilli, R., and Galardi, G. (2015). EEG predictors of outcome in patients with disorders of consciousness admitted for intensive rehabilitation. Clin. Neurophysiol. Off. J. Int. Fed. Clin. Neurophysiol. 126, 959-966.

Bagnato, S., Boccagni, C., Prestandrea, C., Fingelkurts, A.A., Fingelkurts, A.A., and Galardi, G. (2017). Changes in Standard Electroencephalograms Parallel Consciousness Improvements in Patients With Unresponsive Wakefulness Syndrome. Arch. Phys. Med. Rehabil. 98, 665672.

Bai, Y., Liang, Z., Li, X., Voss, L.J., and Sleigh, J.W. (2015). Permutation Lempel-Ziv complexity measure of electroencephalogram in GABAergic anaesthetics. Physiol. Meas. 36, 24832501.

Bailey, C.H., Giustetto, M., Huang, Y.Y., Hawkins, R.D., and Kandel, E.R. (2000). Is heterosynaptic modulation essential for stabilizing Hebbian plasticity and memory? Nat. Rev. Neurosci. 1, 11-20.

Baria, A.T., Centeno, M.V., Ghantous, M.E., Chang, P.C., Procissi, D., and Apkarian, A.V. (2018). BOLD temporal variability differentiates wakefulness from anesthesia-induced unconsciousness. J. Neurophysiol. 119, 834-848.

Beierlein, M. (2014). Synaptic mechanisms underlying cholinergic control of thalamic reticular nucleus neurons. J. Physiol. 592, 4137-4145.

Bennett, C., Voss, L.J., Barnard, J.P.M., and Sleigh, J.W. (2009). Practical use of the raw electroencephalogram waveform during general anesthesia: the art and science. Anesth. Analg. 109, 539-550.

Black, S.W., Morairty, S.R., Chen, T.-M., Leung, A.K., Wisor, J.P., Yamanaka, A., and Kilduff, T.S. (2014). GABAB agonism promotes sleep and reduces cataplexy in murine narcolepsy. J. Neurosci. Off. J. Soc. Neurosci. 34, 6485-6494.

Bonanni, L., Thomas, A., Tiraboschi, P., Perfetti, B., Varanese, S., and Onofrj, M. (2008). EEG comparisons in early Alzheimer's disease, dementia with Lewy bodies and Parkinson's disease with dementia patients with a 2-year follow-up. Brain J. Neurol. 131, 690-705.

Boncompte, G., Medel, V., Cortínez, L.I., and Ossandón, T. (2021). Brain activity complexity has a nonlinear relation to the level of propofol sedation. Br. J. Anaesth. 127, 254-263.

Bouret, S., and Sara, S.J. (2005). Network reset: a simplified overarching theory of locus coeruleus noradrenaline function. Trends Neurosci. 28, 574-582.

Boveroux, P., Bonhomme, V., Boly, M., Vanhaudenhuyse, A., Maquet, P., and Laureys, S. (2008). Brain function in physiologically, pharmacologically, and pathologically altered states of consciousness. Int. Anesthesiol. Clin. 46, 131-146. 
Bowery, N.G. (1993). GABAB receptor pharmacology. Annu. Rev. Pharmacol. Toxicol. 33, 109-147.

Breton, J.-D., and Stuart, G.J. (2017). GABAB receptors in neocortical and hippocampal pyramidal neurons are coupled to different potassium channels. Eur. J. Neurosci. 46, 28592866.

Briel, R.C., McKeith, I.G., Barker, W.A., Hewitt, Y., Perry, R.H., Ince, P.G., and Fairbairn, A.F. (1999). EEG findings in dementia with Lewy bodies and Alzheimer's disease. J. Neurol. Neurosurg. Psychiatry 66, 401-403.

Brito, M.A., Li, D., Mashour, G.A., and Pal, D. (2020). State-Dependent and BandwidthSpecific Effects of Ketamine and Propofol on Electroencephalographic Complexity in Rats. Front. Syst. Neurosci. 14, 50.

Britt, C.W., Raso, E., and Gerson, L.P. (1980). Spindle coma, secondary to primary traumatic midbrain hemorrhage. Electroencephalogr. Clin. Neurophysiol. 49, 406-408.

Brokaw, K., Tishler, W., Manceor, S., Hamilton, K., Gaulden, A., Parr, E., and Wamsley, E.J. (2016). Resting state EEG correlates of memory consolidation. Neurobiol. Learn. Mem. 130, 17-25.

Buzsáki, G., Kennedy, B., Solt, V.B., and Ziegler, M. (1991). Noradrenergic Control of Thalamic Oscillation: the Role of alpha-2 Receptors. Eur. J. Neurosci. 3, 222-229.

Cape, E.G., and Jones, B.E. (2000). Effects of glutamate agonist versus procaine microinjections into the basal forebrain cholinergic cell area upon gamma and theta EEG activity and sleep-wake state. Eur. J. Neurosci. 12, 2166-2184.

Chander, D., García, P.S., MacColl, J.N., Illing, S., and Sleigh, J.W. (2014).

Electroencephalographic variation during end maintenance and emergence from surgical anesthesia. PloS One 9, e106291.

Chatrian, G.E., White, L.E., and Shaw, C.M. (1964). EEG PATTERN RESEMBLING WAKEFULNESS IN UNRESPONSIVE DECEREBRATE STATE FOLLOWING TRAUMATIC BRAINSTEM INFARCT. Electroencephalogr. Clin. Neurophysiol. 16, 285-289.

Chennu, S., Finoia, P., Kamau, E., Allanson, J., Williams, G.B., Monti, M.M., Noreika, V., Arnatkeviciute, A., Canales-Johnson, A., Olivares, F., et al. (2014). Spectral signatures of reorganised brain networks in disorders of consciousness. PLoS Comput. Biol. 10, e1003887.

Ching, S., Cimenser, A., Purdon, P.L., Brown, E.N., and Kopell, N.J. (2010). Thalamocortical model for a propofol-induced alpha-rhythm associated with loss of consciousness. Proc. Natl. Acad. Sci. U. S. A. 107, 22665-22670.

Coenen, A.M., and van Luijtelaar, E.L. (1997). Effects of benzodiazepines, sleep and sleep deprivation on vigilance and memory. Acta Neurol. Belg. 97, 123-129. 
Cohen, M.A., Ortego, K., Kyroudis, A., and Pitts, M. (2020). Distinguishing the Neural Correlates of Perceptual Awareness and Postperceptual Processing. J. Neurosci. Off. J. Soc. Neurosci. 40, 4925-4935.

Collier, B., and Mitchell, J.F. (1967). The central release of acetylcholine during consciousness and after brain lesions. J. Physiol. 188, 83-98.

Cox, E.H., Kuipers, J.A., and Danhof, M. (1998). Pharmacokinetic-pharmacodynamic modelling of the EEG effect of alfentanil in rats: assessment of rapid functional adaptation. Br. J. Pharmacol. 124, 1534-1540.

Dang-Vu, T.T., Bonjean, M., Schabus, M., Boly, M., Darsaud, A., Desseilles, M., Degueldre, C., Balteau, E., Phillips, C., Luxen, A., et al. (2011). Interplay between spontaneous and induced brain activity during human non-rapid eye movement sleep. Proc. Natl. Acad. Sci. U. S. A. 108, 15438-15443.

De Gennaro, L., Ferrara, M., Curcio, G., and Cristiani, R. (2001). Antero-posterior EEG changes during the wakefulness-sleep transition. Clin. Neurophysiol. Off. J. Int. Fed. Clin. Neurophysiol. 112, 1901-1911.

Decker, M.W., and Gallagher, M. (1987). Scopolamine-disruption of radial arm maze performance: modification by noradrenergic depletion. Brain Res. 417, 59-69.

Deshpande, G., Kerssens, C., Sebel, P.S., and Hu, X. (2010). Altered local coherence in the default mode network due to sevoflurane anesthesia. Brain Res. 1318, 110-121.

Dewar, D., and Graham, D.I. (1996). Depletion of choline acetyltransferase activity but preservation of $\mathrm{M} 1$ and $\mathrm{M} 2$ muscarinic receptor binding sites in temporal cortex following head injury: a preliminary human postmortem study. J. Neurotrauma 13, 181-187.

Donat, C.K., Schuhmann, M.U., Voigt, C., Nieber, K., Deuther-Conrad, W., and Brust, P. (2008). Time-dependent alterations of cholinergic markers after experimental traumatic brain injury. Brain Res. 1246, 167-177.

Douglas, C.L., Baghdoyan, H.A., and Lydic, R. (2002). Prefrontal cortex acetylcholine release, EEG slow waves, and spindles are modulated by $\mathrm{M} 2$ autoreceptors in $\mathrm{C} 57 \mathrm{BL} / 6 \mathrm{~J}$ mouse. J. Neurophysiol. 87, 2817-2822.

Dringenberg, H.C., and Diavolitsis, P. (2002). Electroencephalographic activation by fluoxetine in rats: role of $5-\mathrm{HT}(1 \mathrm{~A})$ receptors and enhancement of concurrent acetylcholinesterase inhibitor treatment. Neuropharmacology 42, 154-161.

Dringenberg, H.C., Diavolitsis, P., and Noseworthy, P.A. (2000). Effect of tacrine on EEG slowing in the rat: enhancement by concurrent monoamine therapy. Neurobiol. Aging 21, 135-143.

Duque, A., Balatoni, B., Detari, L., and Zaborszky, L. (2000). EEG correlation of the discharge properties of identified neurons in the basal forebrain. J. Neurophysiol. 84, 1627-1635. 
Ebert, U., Oertel, R., and Kirch, W. (2000). Physostigmine reversal of midazolam-induced electroencephalographic changes in healthy subjects. Clin. Pharmacol. Ther. 67, 538-548.

Englot, D.J., Mishra, A.M., Mansuripur, P.K., Herman, P., Hyder, F., and Blumenfeld, H. (2008). Remote effects of focal hippocampal seizures on the rat neocortex. J. Neurosci. Off. J. Soc. Neurosci. 28, 9066-9081.

Englot, D.J., Modi, B., Mishra, A.M., DeSalvo, M., Hyder, F., and Blumenfeld, H. (2009). Cortical deactivation induced by subcortical network dysfunction in limbic seizures. J. Neurosci. Off. J. Soc. Neurosci. 29, 13006-13018.

Englot, D.J., Yang, L., Hamid, H., Danielson, N., Bai, X., Marfeo, A., Yu, L., Gordon, A., Purcaro, M.J., Motelow, J.E., et al. (2010). Impaired consciousness in temporal lobe seizures: role of cortical slow activity. Brain J. Neurol. 133, 3764-3777.

Eschenko, O., and Sara, S.J. (2008). Learning-dependent, transient increase of activity in noradrenergic neurons of locus coeruleus during slow wave sleep in the rat: brain stemcortex interplay for memory consolidation? Cereb. Cortex N. Y. N 1991 18, 2596-2603.

Fingelkurts, A.A., Fingelkurts, A.A., Bagnato, S., Boccagni, C., and Galardi, G. (2013). The value of spontaneous EEG oscillations in distinguishing patients in vegetative and minimally conscious states. Suppl. Clin. Neurophysiol. 62, 81-99.

Flores, F.J., Hartnack, K.E., Fath, A.B., Kim, S.-E., Wilson, M.A., Brown, E.N., and Purdon, P.L. (2017). Thalamocortical synchronization during induction and emergence from propofolinduced unconsciousness. Proc. Natl. Acad. Sci. U. S. A. 114, E6660-E6668.

Fogerson, P.M., and Huguenard, J.R. (2016). Tapping the Brakes: Cellular and Synaptic Mechanisms that Regulate Thalamic Oscillations. Neuron 92, 687-704.

Francis, P.T., and Perry, E.K. (2007). Cholinergic and other neurotransmitter mechanisms in Parkinson's disease, Parkinson's disease dementia, and dementia with Lewy bodies. Mov. Disord. Off. J. Mov. Disord. Soc. 22 Suppl 17, S351-357.

Frohlich, J., Bird, L.M., Dell'Italia, J., Johnson, M.A., Hipp, J.F., and Monti, M.M. (2020). Highvoltage, diffuse delta rhythms coincide with wakeful consciousness and complexity in Angelman syndrome. Neurosci. Conscious. 2020, niaa005.

Frohlich, J., Toker, D., and Monti, M.M. (2021). Consciousness among delta waves: a paradox? Brain J. Neurol. awab095.

Gais, S., and Born, J. (2004a). Declarative memory consolidation: mechanisms acting during human sleep. Learn. Mem. Cold Spring Harb. N 11, 679-685.

Gais, S., and Born, J. (2004b). Low acetylcholine during slow-wave sleep is critical for declarative memory consolidation. Proc. Natl. Acad. Sci. U. S. A. 101, 2140-2144.

Gaskell, A.L., Hight, D.F., Winders, J., Tran, G., Defresne, A., Bonhomme, V., Raz, A., Sleigh, J.W., and Sanders, R.D. (2017). Frontal alpha-delta EEG does not preclude volitional 
response during anaesthesia: prospective cohort study of the isolated forearm technique. Br. J. Anaesth. 119, 664-673.

Geller, A.S., Burke, J.F., Sperling, M.R., Sharan, A.D., Litt, B., Baltuch, G.H., Lucas, T.H., and Kahana, M.J. (2014). Eye closure causes widespread low-frequency power increase and focal gamma attenuation in the human electrocorticogram. Clin. Neurophysiol. Off. J. Int. Fed. Clin. Neurophysiol. 125, 1764-1773.

Goshen, I., Brodsky, M., Prakash, R., Wallace, J., Gradinaru, V., Ramakrishnan, C., and Deisseroth, K. (2011). Dynamics of retrieval strategies for remote memories. Cell 147, 678689.

Grinberg, L.T., Rüb, U., Ferretti, R.E.L., Nitrini, R., Farfel, J.M., Polichiso, L., Gierga, K., JacobFilho, W., Heinsen, H., and Brazilian Brain Bank Study Group (2009). The dorsal raphe nucleus shows phospho-tau neurofibrillary changes before the transentorhinal region in Alzheimer's disease. A precocious onset? Neuropathol. Appl. Neurobiol. 35, 406-416.

Grindal, A.B., Suter, C., and Martinez, A.J. (1977). Alpha-pattern coma: 24 cases with 9 survivors. Ann. Neurol. 1, 371-377.

Haegens, S., Barczak, A., Musacchia, G., Lipton, M.L., Mehta, A.D., Lakatos, P., and Schroeder, C.E. (2015). Laminar Profile and Physiology of the $\alpha$ Rhythm in Primary Visual, Auditory, and Somatosensory Regions of Neocortex. J. Neurosci. Off. J. Soc. Neurosci. 35, 14341-14352.

Hagihira, S. (2015). Changes in the electroencephalogram during anaesthesia and their physiological basis. Br. J. Anaesth. 115 Suppl 1, i27-i31.

Halgren, M., Ulbert, I., Bastuji, H., Fabó, D., Erőss, L., Rey, M., Devinsky, O., Doyle, W.K., Mak-McCully, R., Halgren, E., et al. (2019). The generation and propagation of the human alpha rhythm. Proc. Natl. Acad. Sci. U. S. A. 116, 23772-23782.

Hars, B., Hennevin, E., and Pasques, P. (1985). Improvement of learning by cueing during postlearning paradoxical sleep. Behav. Brain Res. 18, 241-250.

Hassani, O.K., Lee, M.G., Henny, P., and Jones, B.E. (2009). Discharge profiles of identified GABAergic in comparison to cholinergic and putative glutamatergic basal forebrain neurons across the sleep-wake cycle. J. Neurosci. Off. J. Soc. Neurosci. 29, 11828-11840.

Hassler, R., Ore, G.D., Dieckmann, G., Bricolo, A., and Dolce, G. (1969). Behavioural and EEG arousal induced by stimulation of unspecific projection systems in a patient with posttraumatic apallic syndrome. Electroencephalogr. Clin. Neurophysiol. 27, 306-310.

Hauge, T., Loken, A.C., and Lundervold, A. (1956). Unusual EEG in unconscious patient with brain stem atrophy. Electroencephalogr. Clin. Neurophysiol. 8, 665-670.

Hayashi, R., Hanyu, N., and Yanagisawa, N. (1996). Alpha-pattern coma in primary brainstem hemorrhage; clinical, electrophysiologic, and cerebral blood flow studies. Intern. Med.

Tokyo Jpn. 35, 905-908. 
Hemmings, H.C., Akabas, M.H., Goldstein, P.A., Trudell, J.R., Orser, B.A., and Harrison, N.L. (2005). Emerging molecular mechanisms of general anesthetic action. Trends Pharmacol. Sci. 26, 503-510.

Hemmings, H.C., Riegelhaupt, P.M., Kelz, M.B., Solt, K., Eckenhoff, R.G., Orser, B.A., and Goldstein, P.A. (2019). Towards a Comprehensive Understanding of Anesthetic Mechanisms of Action: A Decade of Discovery. Trends Pharmacol. Sci. 40, 464-481.

Henny, P., and Jones, B.E. (2008). Projections from basal forebrain to prefrontal cortex comprise cholinergic, GABAergic and glutamatergic inputs to pyramidal cells or interneurons. Eur. J. Neurosci. 27, 654-670.

Hesse, S., Kreuzer, M., Hight, D., Gaskell, A., Devari, P., Singh, D., Taylor, N.B., Whalin, M.K., Lee, S., Sleigh, J.W., et al. (2019). Association of electroencephalogram trajectories during emergence from anaesthesia with delirium in the postanaesthesia care unit: an early sign of postoperative complications. Br. J. Anaesth. 122, 622-634.

Heurteaux, C., Guy, N., Laigle, C., Blondeau, N., Duprat, F., Mazzuca, M., Lang-Lazdunski, L., Widmann, C., Zanzouri, M., Romey, G., et al. (2004). TREK-1, a K+ channel involved in neuroprotection and general anesthesia. EMBO J. 23, 2684-2695.

Hight, D., Voss, L.J., Garcia, P.S., and Sleigh, J. (2017). Changes in Alpha Frequency and Power of the Electroencephalogram during Volatile-Based General Anesthesia. Front. Syst. Neurosci. 11, 36.

Hight, D.F., Gaskell, A.L., Kreuzer, M., Voss, L.J., García, P.S., and Sleigh, J.W. (2019). Transient electroencephalographic alpha power loss during maintenance of general anaesthesia. Br. J. Anaesth. 122, 635-642.

Hirota, K., and Roth, S.H. (1997). Sevoflurane modulates both GABAA and GABAB receptors in area CA1 of rat hippocampus. Br. J. Anaesth. 78, 60-65.

Hodor, A., Palchykova, S., Gao, B., and Bassetti, C.L. (2015). Baclofen and gammahydroxybutyrate differentially altered behavior, EEG activity and sleep in rats. Neuroscience $284,18-28$.

Holschneider, D.P., Waite, J.J., Leuchter, A.F., Walton, N.Y., and Scremin, O.U. (1999). Changes in electrocortical power and coherence in response to the selective cholinergic immunotoxin 192 lgG-saporin. Exp. Brain Res. 126, 270-280.

Huupponen, E., Maksimow, A., Lapinlampi, P., Särkelä, M., Saastamoinen, A., Snapir, A., Scheinin, H., Scheinin, M., Meriläinen, P., Himanen, S.-L., et al. (2008).

Electroencephalogram spindle activity during dexmedetomidine sedation and physiological sleep. Acta Anaesthesiol. Scand. 52, 289-294.

Irwin, L.G., and Fortune, D.G. (2014). Risk factors for psychosis secondary to temporal lobe epilepsy: a systematic review. J. Neuropsychiatry Clin. Neurosci. 26, 5-23. 
Isaacson, R.L., Springer, J.E., and Ryan, J.P. (1986). Cholinergic and Catecholaminergic Modification of the Hippocampal Lesion Syndrome. In The Hippocampus: Volume 4, R.L. Isaacson, and K.H. Pribram, eds. (Boston, MA: Springer US), pp. 127-158.

Jäkälä, P., Sirviö, J., Koivisto, E., Björklund, M., Kaukua, J., and Riekkinen, P. (1995). Modulation of rat neocortical high-voltage spindle activity by 5-HT1/5-HT2 receptor subtype specific drugs. Eur. J. Pharmacol. 282, 39-55.

Jäkälä, P., Björklund, M., Koivisto, E., and Riekkinen, P. (1996). The effects of cholinergic drugs on rat neocortical high-voltage spindles in ketanserin-treated rats. Eur. J. Pharmacol. 316, 181-193.

Jang, S.H., and Kwon, Y.H. (2019). Neuroimaging characterization of recovery of impaired consciousness in patients with disorders of consciousness. Neural Regen. Res. 14, 12021207.

Jang, S., Kim, S., and Lee, H. (2016). Recovery From Vegetative State to Minimally Conscious State: A Case Report. Am. J. Phys. Med. Rehabil. 95, e63-66.

Joo, H.R., and Frank, L.M. (2018). The hippocampal sharp wave-ripple in memory retrieval for immediate use and consolidation. Nat. Rev. Neurosci. 19, 744-757.

Jurd, R., Arras, M., Lambert, S., Drexler, B., Siegwart, R., Crestani, F., Zaugg, M., Vogt, K.E., Ledermann, B., Antkowiak, B., et al. (2003). General anesthetic actions in vivo strongly attenuated by a point mutation in the GABA(A) receptor beta3 subunit. FASEB J. Off. Publ. Fed. Am. Soc. Exp. Biol. 17, 250-252.

Karni, A., Tanne, D., Rubenstein, B.S., Askenasy, J.J., and Sagi, D. (1994). Dependence on REM sleep of overnight improvement of a perceptual skill. Science 265, 679-682.

Kaur, S., Junek, A., Black, M.A., and Semba, K. (2008). Effects of ibotenate and 192IgGsaporin lesions of the nucleus basalis magnocellularis/substantia innominata on spontaneous sleep and wake states and on recovery sleep after sleep deprivation in rats. J. Neurosci. Off. J. Soc. Neurosci. 28, 491-504.

Keifer, J.C., Baghdoyan, H.A., Becker, L., and Lydic, R. (1994). Halothane decreases pontine acetylcholine release and increases EEG spindles. Neuroreport 5, 577-580.

Khodagholy, D., Gelinas, J.N., and Buzsáki, G. (2017). Learning-enhanced coupling between ripple oscillations in association cortices and hippocampus. Science 358, 369-372.

Kim, T., Thankachan, S., McKenna, J.T., McNally, J.M., Yang, C., Choi, J.H., Chen, L., Kocsis, B. Deisseroth, K., Strecker, R.E., et al. (2015). Cortically projecting basal forebrain parvalbumin neurons regulate cortical gamma band oscillations. Proc. Natl. Acad. Sci. U. S. A. 112, 35353540 .

Kimura, T., Saunders, P.A., Yamamoto, I., and Ho, I.K. (1991). Effects of pentobarbital tolerance to and dependence on GABAB receptor-binding. Neurochem. Res. 16, 1133-1137. 
Kitamura, T., Ogawa, S.K., Roy, D.S., Okuyama, T., Morrissey, M.D., Smith, L.M., Redondo, R.L., and Tonegawa, S. (2017). Engrams and circuits crucial for systems consolidation of a memory. Science 356, 73-78.

Kochs, E., Bischoff, P., Pichlmeier, U., and Schulte am Esch, J. (1994). Surgical stimulation induces changes in brain electrical activity during isoflurane/nitrous oxide anesthesia. A topographic electroencephalographic analysis. Anesthesiology 80, 1026-1034.

Kometer, M., Schmidt, A., Jäncke, L., and Vollenweider, F.X. (2013). Activation of serotonin $2 A$ receptors underlies the psilocybin-induced effects on $\alpha$ oscillations, N170 visual-evoked potentials, and visual hallucinations. J. Neurosci. Off. J. Soc. Neurosci. 33, 10544-10551.

Kristiansen, K., and Courtois, G. (1949). Rhythmic electrical activity from isolated cerebral cortex. Electroencephalogr. Clin. Neurophysiol. 1, 265-272.

Landsness, E., Bruno, M.-A., Noirhomme, Q., Riedner, B., Gosseries, O., Schnakers, C., Massimini, M., Laureys, S., Tononi, G., and Boly, M. (2011). Electrophysiological correlates of behavioural changes in vigilance in vegetative state and minimally conscious state. Brain J. Neurol. 134, 2222-2232.

Laureys, S., Antoine, S., Boly, M., Elincx, S., Faymonville, M.-E., Berré, J., Sadzot, B., Ferring, M., De Tiège, X., van Bogaert, P., et al. (2002). Brain function in the vegetative state. Acta Neurol. Belg. 102, 177-185.

Lawhern, V., Kerick, S., and Robbins, K.A. (2013). Detecting alpha spindle events in EEG time series using adaptive autoregressive models. BMC Neurosci. 14, 101.

Lechinger, J., Bothe, K., Pichler, G., Michitsch, G., Donis, J., Klimesch, W., and Schabus, M. (2013). CRS-R score in disorders of consciousness is strongly related to spectral EEG at rest. J. Neurol. 260, 2348-2356.

Lee, K.H., Meador, K.J., Park, Y.D., King, D.W., Murro, A.M., Pillai, J.J., and Kaminski, R.J. (2002). Pathophysiology of altered consciousness during seizures: Subtraction SPECT study. Neurology 59, 841-846.

Li, Y., Xu, J., Xu, Y., Zhao, X.-Y., Liu, Y., Wang, J., Wang, G.-M., Lv, Y.-T., Tang, Q.-Y., and Zhang, Z. (2018). Regulatory Effect of General Anesthetics on Activity of Potassium Channels. Neurosci. Bull. 34, 887-900.

Liberati, G., Hünefeldt, T., and Olivetti Belardinelli, M. (2014). Questioning the dichotomy between vegetative state and minimally conscious state: a review of the statistical evidence. Front. Hum. Neurosci. 8, 865.

Lin, L.H., Leonard, S., and Harris, R.A. (1993). Enflurane inhibits the function of mouse and human brain phosphatidylinositol-linked acetylcholine and serotonin receptors expressed in Xenopus oocytes. Mol. Pharmacol. 43, 941-948. 
Lin, W.-H., Huang, H.-P., Lin, M.-X., Chen, S.-G., Lv, X.-C., Che, C.-H., and Lin, J.-L. (2013). Seizure-induced 5-HT release and chronic impairment of serotonergic function in rats. Neurosci. Lett. 534, 1-6.

Lindsley, D.B., Bowden, J.W., and Magoun, H.W. (1949). Effect upon the EEG of acute injury to the brain stem activating system. Electroencephalogr. Clin. Neurophysiol. 1, 475-486.

Liu, X., Ramirez, S., Pang, P.T., Puryear, C.B., Govindarajan, A., Deisseroth, K., and Tonegawa, S. (2012). Optogenetic stimulation of a hippocampal engram activates fear memory recall. Nature 484, 381-385.

Lledo, P.-M., Alonso, M., and Grubb, M.S. (2006). Adult neurogenesis and functional plasticity in neuronal circuits. Nat. Rev. Neurosci. 7, 179-193.

Loeb, C., and Poggio, G. (1953). Electroencephalograms in a case with ponto-mesencephalic haemorrhage. Electroencephalogr. Clin. Neurophysiol. 5, 295-296.

Lu, J., Nelson, L.E., Franks, N., Maze, M., Chamberlin, N.L., and Saper, C.B. (2008). Role of endogenous sleep-wake and analgesic systems in anesthesia. J. Comp. Neurol. 508, 648662.

Lucassen, P.J., Fitzsimons, C.P., Salta, E., and Maletic-Savatic, M. (2020). Adult neurogenesis, human after all (again): Classic, optimized, and future approaches. Behav. Brain Res. 381, 112458.

Maity, S., Rah, S., Sonenberg, N., Gkogkas, C.G., and Nguyen, P.V. (2015). Norepinephrine triggers metaplasticity of LTP by increasing translation of specific mRNAs. Learn. Mem. Cold Spring Harb. N 22, 499-508.

Mak-McCully, R.A., Rolland, M., Sargsyan, A., Gonzalez, C., Magnin, M., Chauvel, P., Rey, M., Bastuji, H., and Halgren, E. (2017). Coordination of cortical and thalamic activity during nonREM sleep in humans. Nat. Commun. 8, 15499.

Manfridi, A., Brambilla, D., and Mancia, M. (1999). Stimulation of NMDA and AMPA receptors in the rat nucleus basalis of Meynert affects sleep. Am. J. Physiol. 277, R14881492.

McCormick, D.A., Wang, Z., and Huguenard, J. (1993). Neurotransmitter control of neocortical neuronal activity and excitability. Cereb. Cortex N. Y. N 1991 3, 387-398.

McGaugh, J.L., Introini-Collison, I.B., Cahill, L.F., Castellano, C., Dalmaz, C., Parent, M.B., and Williams, C.L. (1993). Neuromodulatory systems and memory storage: role of the amygdala. Behav. Brain Res. 58, 81-90.

Mednick, S.C., McDevitt, E.A., Walsh, J.K., Wamsley, E., Paulus, M., Kanady, J.C., and Drummond, S.P.A. (2013). The critical role of sleep spindles in hippocampal-dependent memory: a pharmacology study. J. Neurosci. Off. J. Soc. Neurosci. 33, 4494-4504.

Mesulam, M.-M. (2013). Cholinergic circuitry of the human nucleus basalis and its fate in Alzheimer's disease. J. Comp. Neurol. 521, 4124-4144. 
Meuret, P., Backman, S.B., Bonhomme, V., Plourde, G., and Fiset, P. (2000). Physostigmine reverses propofol-induced unconsciousness and attenuation of the auditory steady state response and bispectral index in human volunteers. Anesthesiology 93, 708-717.

Monteiro Moreira, K., Lima Ferreira, T., Vecchio Fornari, R., Perez Figueredo, L.Z., and Menezes Oliveira, M.G. (2005). Interaction between M1-muscarinic and glutamatergic NMDA receptors on an inhibitory avoidance task. Brain Res. Bull. 67, 504-508.

Monti, null, and Jantos, null (1992). Dose-dependent effects of the 5-HT1A receptor agonist 8-OH-DPAT on sleep and wakefulness in the rat. J. Sleep Res. 1, 169-175.

Monti, M.M., Coleman, M.R., and Owen, A.M. (2009). Neuroimaging and the vegetative state: resolving the behavioral assessment dilemma? Ann. N. Y. Acad. Sci. 1157, 81-89.

Monti, M.M., Vanhaudenhuyse, A., Coleman, M.R., Boly, M., Pickard, J.D., Tshibanda, L., Owen, A.M., and Laureys, S. (2010). Willful modulation of brain activity in disorders of consciousness. N. Engl. J. Med. 362, 579-589.

Moyanova, S., Kortenska, L., and Kirov, R. (1998). High-voltage electroencephalogram spindles in rats, aging and 5-HT2 antagonism. Brain Res. 786, 55-63.

Murasaki, O., Kaibara, M., Nagase, Y., Mitarai, S., Doi, Y., Sumikawa, K., and Taniyama, K. (2003). Site of action of the general anesthetic propofol in muscarinic M1 receptormediated signal transduction. J. Pharmacol. Exp. Ther. 307, 995-1000.

Murdoch, I., Nicoll, J.A.R., Graham, D.I., and Dewar, D. (2002). Nucleus basalis of Meynert pathology in the human brain after fatal head injury. J. Neurotrauma 19, 279-284.

Nanda, B., Galvan, A., Smith, Y., and Wichmann, T. (2009). Effects of stimulation of the centromedian nucleus of the thalamus on the activity of striatal cells in awake rhesus monkeys. Eur. J. Neurosci. 29, 588-598.

Neckelmann, D., Bjørkum, A.A., Bjorvatn, B., and Ursin, R. (1996). Sleep and EEG power spectrum effects of the 5-HT1A antagonist NAN-190 alone and in combination with citalopram. Behav. Brain Res. 75, 159-168.

Ni, K.-M., Hou, X.-J., Yang, C.-H., Dong, P., Li, Y., Zhang, Y., Jiang, P., Berg, D.K., Duan, S., and $\mathrm{Li}, \mathrm{X}$.-M. (2016). Selectively driving cholinergic fibers optically in the thalamic reticular nucleus promotes sleep. ELife 5.

Novitskaya, Y., Sara, S.J., Logothetis, N.K., and Eschenko, O. (2016). Ripple-triggered stimulation of the locus coeruleus during post-learning sleep disrupts ripple/spindle coupling and impairs memory consolidation. Learn. Mem. Cold Spring Harb. N 23, 238-248.

Nuñez, A., Curró Dossi, R., Contreras, D., and Steriade, M. (1992). Intracellular evidence for incompatibility between spindle and delta oscillations in thalamocortical neurons of cat. Neuroscience 48, 75-85.

O'Connell, A.D., Morton, M.J., and Hunter, M. (2002). Two-pore domain K+ channelsmolecular sensors. Biochim. Biophys. Acta 1566, 152-161. 
Owen, A.M., Coleman, M.R., Boly, M., Davis, M.H., Laureys, S., and Pickard, J.D. (2006). Detecting awareness in the vegetative state. Science 313, 1402.

Pal, D., Li, D., Dean, J.G., Brito, M.A., Liu, T., Fryzel, A.M., Hudetz, A.G., and Mashour, G.A. (2020). Level of Consciousness Is Dissociable from Electroencephalographic Measures of Cortical Connectivity, Slow Oscillations, and Complexity. J. Neurosci. Off. J. Soc. Neurosci. 40, 605-618.

Patel, A.J., Honoré, E., Lesage, F., Fink, M., Romey, G., and Lazdunski, M. (1999). Inhalational anesthetics activate two-pore-domain background K+ channels. Nat. Neurosci. 2, 422-426.

Pavel, M.A., Petersen, E.N., Wang, H., Lerner, R.A., and Hansen, S.B. (2020). Studies on the mechanism of general anesthesia. Proc. Natl. Acad. Sci. U. S. A. 117, 13757-13766.

Pavone, K.J., Su, L., Gao, L., Eromo, E., Vazquez, R., Rhee, J., Hobbs, L.E., Ibala, R., Demircioglu, G., Purdon, P.L., et al. (2017). Lack of Responsiveness during the Onset and Offset of Sevoflurane Anesthesia Is Associated with Decreased Awake-Alpha Oscillation Power. Front. Syst. Neurosci. 11, 38.

Perry, E.K., Irving, D., Kerwin, J.M., McKeith, I.G., Thompson, P., Collerton, D., Fairbairn, A.F., Ince, P.G., Morris, C.M., and Cheng, A.V. (1993). Cholinergic transmitter and neurotrophic activities in Lewy body dementia: similarity to Parkinson's and distinction from Alzheimer disease. Alzheimer Dis. Assoc. Disord. 7, 69-79.

Plihal, W., and Born, J. (1997). Effects of early and late nocturnal sleep on declarative and procedural memory. J. Cogn. Neurosci. 9, 534-547.

Plourde, G., and Picton, T.W. (1991). Long-latency auditory evoked potentials during general anesthesia: N1 and P3 components. Anesth. Analg. 72, 342-350.

Prichep, L.S., John, E.R., Ferris, S.H., Reisberg, B., Almas, M., Alper, K., and Cancro, R. (1994). Quantitative EEG correlates of cognitive deterioration in the elderly. Neurobiol. Aging 15, 85-90.

Puoliväli, J., Jäkälä, P., Koivisto, E., and Riekkinen, P. (1998). Muscarinic M1 and M2 receptor subtype selective drugs modulate neocortical EEG via thalamus. Neuroreport 9, 1685-1689.

Purdon, P.L., Pierce, E.T., Mukamel, E.A., Prerau, M.J., Walsh, J.L., Wong, K.F.K., SalazarGomez, A.F., Harrell, P.G., Sampson, A.L., Cimenser, A., et al. (2013). Electroencephalogram signatures of loss and recovery of consciousness from propofol. Proc. Natl. Acad. Sci. U. S. A. 110, E1142-1151.

Purdon, P.L., Pavone, K.J., Akeju, O., Smith, A.C., Sampson, A.L., Lee, J., Zhou, D.W., Solt, K., and Brown, E.N. (2015). The Ageing Brain: Age-dependent changes in the electroencephalogram during propofol and sevoflurane general anaesthesia. Br. J. Anaesth. 115 Suppl 1, i46-i57. 
Ramirez-Villegas, J.F., Logothetis, N.K., and Besserve, M. (2015). Diversity of sharp-waveripple LFP signatures reveals differentiated brain-wide dynamical events. Proc. Natl. Acad. Sci. U. S. A. 112, E6379-6387.

Richter-Levin, G., and Segal, M. (1989). Spatial performance is severely impaired in rats with combined reduction of serotonergic and cholinergic transmission. Brain Res. 477, 404-407.

Riekkinen, P., Sirviö, J., Valjakka, A., Miettinen, R., and Riekkinen, P. (1991). Pharmacological consequences of cholinergic plus serotonergic manipulations. Brain Res. 552, 23-26.

Riekkinen, P., Sirviö, J., Toivanen, L., Riekkinen, M., Lammintausta, R., and Riekkinen, P. (1993). Alpha 1-adrenoceptor antagonist decreases alpha 2-adrenoceptor antagonistinduced high voltage spindle suppression in adult and aged rats. Eur. J. Pharmacol. 235, 317-320.

Rouse, S.T., and Levey, A.I. (1996). Expression of m1-m4 muscarinic acetylcholine receptor immunoreactivity in septohippocampal neurons and other identified hippocampal afferents. J. Comp. Neurol. 375, 406-416.

Rüb, U., Del Tredici, K., Schultz, C., Thal, D.R., Braak, E., and Braak, H. (2000). The evolution of Alzheimer's disease-related cytoskeletal pathology in the human raphe nuclei. Neuropathol. Appl. Neurobiol. 26, 553-567.

Salgado-Seixas, F., Pereira, R., Machado, H., and Cavaleiro, C. (2020). Misinterpretation and Limitations of pEEG Monitoring During Multimodal General Anesthesia: A Case Report. AA Pract. 14, 109-111.

Salmond, C.H., Chatfield, D.A., Menon, D.K., Pickard, J.D., and Sahakian, B.J. (2005). Cognitive sequelae of head injury: involvement of basal forebrain and associated structures. Brain J. Neurol. 128, 189-200.

Sara, S.J., and Segal, M. (1991). Plasticity of sensory responses of locus coeruleus neurons in the behaving rat: implications for cognition. Prog. Brain Res. 88, 571-585.

Sarasso, S., Boly, M., Napolitani, M., Gosseries, O., Charland-Verville, V., Casarotto, S., Rosanova, M., Casali, A.G., Brichant, J.-F., Boveroux, P., et al. (2015). Consciousness and Complexity during Unresponsiveness Induced by Propofol, Xenon, and Ketamine. Curr. Biol. CB 25, 3099-3105.

Saxe, M.D., Battaglia, F., Wang, J.-W., Malleret, G., David, D.J., Monckton, J.E., Garcia, A.D.R., Sofroniew, M.V., Kandel, E.R., Santarelli, L., et al. (2006). Ablation of hippocampal neurogenesis impairs contextual fear conditioning and synaptic plasticity in the dentate gyrus. Proc. Natl. Acad. Sci. U. S. A. 103, 17501-17506.

Schaul, N., Gloor, P., Ball, G., and Gotman, J. (1978). The electromicrophysiology of delta waves induced by systemic atropine. Brain Res. 143, 475-486. 
Schiff, N.D., Giacino, J.T., Kalmar, K., Victor, J.D., Baker, K., Gerber, M., Fritz, B., Eisenberg, B., Biondi, T., O'Connor, J., et al. (2007). Behavioural improvements with thalamic stimulation after severe traumatic brain injury. Nature 448, 600-603.

Schmidt, R.H., and Grady, M.S. (1995). Loss of forebrain cholinergic neurons following fluidpercussion injury: implications for cognitive impairment in closed head injury. J. Neurosurg. 83, 496-502.

Schwieler, L., Delbro, D.S., Engberg, G., and Erhardt, S. (2003). The anaesthetic agent propofol interacts with GABA(B)-receptors: an electrophysiological study in rat. Life Sci. 72, 2793-2801.

Sebel, P.S., Bovill, J.G., Wauquier, A., and Rog, P. (1981). Effects of high-dose fentanyl anesthesia on the electroencephalogram. Anesthesiology 55, 203-211.

Sejnowski, T.J., and Destexhe, A. (2000). Why do we sleep? Brain Res. 886, 208-223.

Sergent, C., Corazzol, M., Labouret, G., Stockart, F., Wexler, M., King, J.-R., Meyniel, F., and Pressnitzer, D. (2021). Bifurcation in brain dynamics reveals a signature of conscious processing independent of report. Nat. Commun. 12, 1149.

Shao, Y.R., Kahali, P., Houle, T.T., Deng, H., Colvin, C., Dickerson, B.C., Brown, E.N., and Purdon, P.L. (2020). Low Frontal Alpha Power Is Associated With the Propensity for Burst Suppression: An Electroencephalogram Phenotype for a "Vulnerable Brain." Anesth. Analg.

Shors, T.J., Miesegaes, G., Beylin, A., Zhao, M., Rydel, T., and Gould, E. (2001). Neurogenesis in the adult is involved in the formation of trace memories. Nature 410, 372-376.

Siapas, A.G., and Wilson, M.A. (1998). Coordinated interactions between hippocampal ripples and cortical spindles during slow-wave sleep. Neuron 21, 1123-1128.

da Silva, F.H., van Lierop, T.H., Schrijer, C.F., and van Leeuwen, W.S. (1973). Essential differences between alpha rhythms and barbiturate spindles: spectra and thalamo-cortical coherences. Electroencephalogr. Clin. Neurophysiol. 35, 641-645.

Sleigh, J.W., Scheib, C.M., and Sanders, R.D. (2011). General anaesthesia and electroencephalographic spindles. Trends Anaesth. Crit. Care 1, 263-269.

Smith, C.T., Aubrey, J.B., and Peters, K.R. (2004a). Different Roles for REM and Stage 2 Sleep in Motor Learning: A Proposed Model. Psychol. Belg. 44, 81-104.

Smith, Y., Raju, D.V., Pare, J.-F., and Sidibe, M. (2004b). The thalamostriatal system: a highly specific network of the basal ganglia circuitry. Trends Neurosci. 27, 520-527.

Sneyd, J.R., Samra, S.K., Davidson, B., Kishimoto, T., Kadoya, C., and Domino, E.F. (1994). Electrophysiologic effects of propofol sedation. Anesth. Analg. 79, 1151-1158.

Squire, L.R., Genzel, L., Wixted, J.T., and Morris, R.G. (2015). Memory consolidation. Cold Spring Harb. Perspect. Biol. 7, a021766. 
Staresina, B.P., Bergmann, T.O., Bonnefond, M., van der Meij, R., Jensen, O., Deuker, L., Elger, C.E., Axmacher, N., and Fell, J. (2015). Hierarchical nesting of slow oscillations, spindles and ripples in the human hippocampus during sleep. Nat. Neurosci. 18, 1679-1686.

Stephen, E.P., Hotan, G.C., Pierce, E.T., Harrell, P.G., Walsh, J.L., Brown, E.N., and Purdon, P.L. (2020). Broadband slow-wave modulation in posterior and anterior cortex tracks distinct states of propofol-induced unconsciousness. Sci. Rep. 10, 13701.

Stickgold, R., Fosse, R., and Walker, M.P. (2002). Linking brain and behavior in sleepdependent learning and memory consolidation. Proc. Natl. Acad. Sci. U. S. A. 99, 1651916521.

Straube, T., Korz, V., Balschun, D., and Frey, J.U. (2003). Requirement of beta-adrenergic receptor activation and protein synthesis for LTP-reinforcement by novelty in rat dentate gyrus. J. Physiol. 552, 953-960.

Sugimura, M., Kitayama, S., Morita, K., Imai, Y., Irifune, M., Takarada, T., Kawahara, M., and Dohi, T. (2002). Effects of GABAergic agents on anesthesia induced by halothane, isoflurane, and thiamylal in mice. Pharmacol. Biochem. Behav. 72, 111-116.

Suh, B.-C., and Hille, B. (2005). Regulation of ion channels by phosphatidylinositol 4,5bisphosphate. Curr. Opin. Neurobiol. 15, 370-378.

Sun, A.X., Yuan, Q., Fukuda, M., Yu, W., Yan, H., Lim, G.G.Y., Nai, M.H., D’Agostino, G.A., Tran, H.-D., Itahana, Y., et al. (2019). Potassium channel dysfunction in human neuronal models of Angelman syndrome. Science 366, 1486-1492.

Supp, G.G., Siegel, M., Hipp, J.F., and Engel, A.K. (2011). Cortical hypersynchrony predicts breakdown of sensory processing during loss of consciousness. Curr. Biol. CB 21, 1988-1993.

Sutter, R., and Kaplan, P.W. (2012). Electroencephalographic patterns in coma: when things slow down. Epileptologie 29, 201-209.

Swift, K.M., Gross, B.A., Frazer, M.A., Bauer, D.S., Clark, K.J.D., Vazey, E.M., Aston-Jones, G., Li, Y., Pickering, A.E., Sara, S.J., et al. (2018). Abnormal Locus Coeruleus Sleep Activity Alters Sleep Signatures of Memory Consolidation and Impairs Place Cell Stability and Spatial Memory. Curr. Biol. CB 28, 3599-3609.e4.

Talakoub, O., Sayegh, P., Womelsdorf, T., Zinke, W., Fries, P., Lewis, C.M., and Hoffman, K.L. (2019). Hippocampal and neocortical oscillations are tuned to behavioral state in freelybehaving macaques.

Taylor, N., Graham, M., Delargy, M., and Naci, L. (2020). Memory During the Presumed Vegetative State: Implications for Patient Quality of Life. Camb. Q. Healthc. Ethics CQ Int. J. Healthc. Ethics Comm. 29, 501-510.

Tiraboschi, P., Hansen, L.A., Alford, M., Merdes, A., Masliah, E., Thal, L.J., and Corey-Bloom, J. (2002). Early and widespread cholinergic losses differentiate dementia with Lewy bodies from Alzheimer disease. Arch. Gen. Psychiatry 59, 946-951. 
Tomassen, W., and Kamphuisen, H.A. (1986). Alpha coma. J. Neurol. Sci. 76, 1-11.

Toni, N., Laplagne, D.A., Zhao, C., Lombardi, G., Ribak, C.E., Gage, F.H., and Schinder, A.F. (2008). Neurons born in the adult dentate gyrus form functional synapses with target cells. Nat. Neurosci. 11, 901-907.

Trulson, M.E., and Jacobs, B.L. (1979). Raphe unit activity in freely moving cats: correlation with level of behavioral arousal. Brain Res. 163, 135-150.

UI Haq, R., Liotta, A., Kovacs, R., Rösler, A., Jarosch, M.J., Heinemann, U., and Behrens, C.J. (2012). Adrenergic modulation of sharp wave-ripple activity in rat hippocampal slices. Hippocampus 22, 516-533.

Ulrich, D., Lalanne, T., Gassmann, M., and Bettler, B. (2018). GABAB receptor subtypes differentially regulate thalamic spindle oscillations. Neuropharmacology 136, 106-116.

Vakalopoulos, C. (2005a). A theory of blindsight--the anatomy of the unconscious: a proposal for the koniocellular projections and intralaminar thalamus. Med. Hypotheses 65, 1183-1190.

Vakalopoulos, C. (2005b). Neural correlates of consciousness: a definition of the dorsal and ventral streams and their relation to phenomenology. Med. Hypotheses 65, 922-931.

Vakalopoulos, C. (2006). Neuropharmacology of cognition and memory: a unifying theory of neuromodulator imbalance in psychiatry and amnesia. Med. Hypotheses 66, 394-431.

Vakalopoulos, C. (2008). A hand in the blindsight paradox: a subcortical pathway? Neuropsychologia 46, 3239-3240.

Vakalopoulos, C. (2013). A cholinergic hypothesis of the unconscious in affective disorders. Front. Neurosci. 7, 220.

Vakalopoulos, C. (2014). The EEG as an index of neuromodulator balance in memory and mental illness. Front. Neurosci. 8, 63.

Valko, P.O., Gavrilov, Y.V., Yamamoto, M., Noaín, D., Reddy, H., Haybaeck, J., Weis, S., Baumann, C.R., and Scammell, T.E. (2016). Damage to Arousal-Promoting Brainstem Neurons with Traumatic Brain Injury. Sleep 39, 1249-1252.

VanDongen, A.M., Codina, J., Olate, J., Mattera, R., Joho, R., Birnbaumer, L., and Brown, A.M. (1988). Newly identified brain potassium channels gated by the guanine nucleotide binding protein Go. Science 242, 1433-1437.

Walter, U., Fernández-Torre, J.L., Kirschstein, T., and Laureys, S. (2018). When is "brainstem death" brain death? The case for ancillary testing in primary infratentorial brain lesion. Clin. Neurophysiol. Off. J. Int. Fed. Clin. Neurophysiol. 129, 2451-2465.

Wan, L., Huang, H., Schwab, N., Tanner, J., Rajan, A., Lam, N.B., Zaborszky, L., Li, C.-S.R., Price, C.C., and Ding, M. (2019). From eyes-closed to eyes-open: Role of cholinergic 
projections in EC-to-EO alpha reactivity revealed by combining EEG and MRI. Hum. Brain Mapp. 40, 566-577.

Watabe, A.M., Zaki, P.A., and O'Dell, T.J. (2000). Coactivation of beta-adrenergic and cholinergic receptors enhances the induction of long-term potentiation and synergistically activates mitogen-activated protein kinase in the hippocampal CA1 region. J. Neurosci. Off. J. Soc. Neurosci. 20, 5924-5931.

Wauquier, A., De Ryck, M., Van den Broeck, W., Van Loon, J., Melis, W., and Janssen, P. (1988). Relationships between quantitative EEG measures and pharmacodynamics of alfentanil in dogs. Electroencephalogr. Clin. Neurophysiol. 69, 550-560.

Weigl, L.G., and Schreibmayer, W. (2001). G protein-gated inwardly rectifying potassium channels are targets for volatile anesthetics. Mol. Pharmacol. 60, 282-289.

Weingartner, H.J., Joyce, E.M., Sirocco, K.Y., Adams, C.M., Eckardt, M.J., George, T., and Lister, R.G. (1993). Specific memory and sedative effects of the benzodiazepine triazolam. J. Psychopharmacol. Oxf. Engl. 7, 305-315.

Westmoreland, B.F., Klass, D.W., Sharbrough, F.W., and Reagan, T.J. (1975). Alpha-coma. Electroencephalographic, clinical, pathologic, and etiologic correlations. Arch. Neurol. 32, 713-718.

Wollstadt, P., Sellers, K.K., Hutt, A., Frohlich, F., and Wibral, M. (2015). Anesthesia-related changes in information transfer may be caused by reduction in local information generation. Annu. Int. Conf. IEEE Eng. Med. Biol. Soc. IEEE Eng. Med. Biol. Soc. Annu. Int. Conf. 2015, 4045-4048.

Xi, C., Sun, S., Pan, C., Ji, F., Cui, X., and Li, T. (2018). Different effects of propofol and dexmedetomidine sedation on electroencephalogram patterns: Wakefulness, moderate sedation, deep sedation and recovery. PloS One 13, e0199120.

Xuan, F.-L., Wang, H.-W., Cao, L.-X., Bing, Y.-H., Chu, C.-P., Jin, R., and Qiu, D.-L. (2018). Propofol Inhibits Cerebellar Parallel Fiber-Purkinje Cell Synaptic Transmission via Activation of Presynaptic GABAB Receptors in vitro in Mice. Front. Neurosci. 12, 922.

Yamamoto, T., and Hirano, A. (1985). Nucleus raphe dorsalis in Alzheimer's disease: neurofibrillary tangles and loss of large neurons. Ann. Neurol. 17, 573-577.

Yang, B., Wang, B., Lai, M., Zhang, F., Yang, X., Zhou, W., and Lian, Q. (2011). Differential involvement of GABAA and GABAB receptors in propofol self-administration in rats. Acta Pharmacol. Sin. 32, 1460-1465.

Yppärilä, H., Korhonen, I., Tarvainen, M., Musialowicz, T., Jakob, S.M., and Partanen, J. (2004). N100 auditory potential and electroencephalogram discriminate propofol-induced sedation levels. J. Clin. Monit. Comput. 18, 163-170. 
Yu, H., Lv, D., Shen, M., Zhang, Y., Zhou, D., Chen, Z., and Wang, C. (2019). BDNF mediates the protective effects of scopolamine in reserpine-induced depression-like behaviors via upregulation of 5-HTT and TPH1. Psychiatry Res. 271, 328-334.

van der Zande, J.J., Gouw, A.A., van Steenoven, I., van de Beek, M., Scheltens, P., Stam, C.J., and Lemstra, A.W. (2020). Diagnostic and prognostic value of EEG in prodromal dementia with Lewy bodies. Neurology 95, e662-e670. 